\title{
Hypermethylation of Mest Promoter Causes Aberrant Wnt Signaling in the Patients of Alzheimer's Disease
}

\section{Renuka Prasad}

University of Seoul

\section{Hwajin Jung}

University of Seoul College of Natural Sciences

Anderson Tan

University of Seoul College of Natural Sciences

\section{Yonghee Song}

University of Seoul College of Natural Sciences

\section{Sungho Moon}

University of Seoul College of Natural Sciences

Mohammed R. Shaker

Korea University College of Medicine and School of Medicine

\section{Woong Sun}

Korea University College of Medicine and School of Medicine

\section{Junghee Lee}

Boston University School of Medicine

Hoon Ryu

Korea Institute of Science and Technology

Hyun Kook Lim

Catholic University of Korea

Eek-hoon Jho ( $\nabla$ ej70@uos.ac.kr)

University of Seoul https://orcid.org/0000-0003-2414-6234

\section{Research article}

Keywords: Mest, Hypermethylation, Wnt signaling, Neurodegeneration, Alzheimer's disease.

Posted Date: May 6th, 2021

DOI: https://doi.org/10.21203/rs.3.rs-474622/v1 
License: (c) (i) This work is licensed under a Creative Commons Attribution 4.0 International License. Read Full License 


\section{Hypermethylation of Mest promoter causes aberrant}

\section{Wnt signaling in the patients of Alzheimer's disease}

Renuka Prasad ${ }^{1, \dagger}$, Hwajin Jung ${ }^{1, \dagger}$, Anderson Tan ${ }^{1}$, Yonghee Song ${ }^{1}$, Sungho Moon ${ }^{1}$,

Mohammed R. Shaker ${ }^{2}$, Woong Sun², Junghee Lee ${ }^{3}$, Hoon Ryu ${ }^{3} 4^{*}$, Hyun Kook Lim ${ }^{*}$ and

Eek-hoon $\mathrm{Jho}^{1^{*}}$

† These authors contributed equally to this work

*To whom correspondence may be addressed.

E-mail: hoonryu@bu.edu, drblues@catholic.ac.kr, ej70@uos.ac.kr

1 Department of Life science, University of Seoul, Seoul, Republic of Korea, 130-743, Republic of Korea

Full list of author information is available at the end of the article

Renuka Prasad: prasadcology@gmail.com

Hwajin Jung: junghgm@gmail.com

Anderson Tan: tananderson89@gmail.com

Yonghee Song: blackraven-x@hanmail.net

Sungho Moon: moon20000@uos.ac.kr

Mohammed R. Shaker: neuromesodermal@gmail.com

Woong Sun: woongsun@korea.ac.kr

Junghee Lee: junghee@bu.edu

Hoon Ryu: hoonryu@bu.edu

Hyun Kook Lim: drblues@catholic.ac.kr

Eek-hoon Jho: ej70@uos.ac.kr 


\section{Abstract}

Background: The expression of mesoderm-specific transcript (Mest) is regulated by genomic imprinting where only the paternal allele is active for transcription. Mest is a candidate gene for Silver-Russell Syndrome, and hypermethylation of Mest promoter is associated with oligozoospermia. In addition, Loss of imprinting (LOI) is often associated with various neurodegenerative diseases and cancers. Since aberrant Mest hypermethylation and LOI are implicated in various diseases, it is vital to study Mest promoter hypermethylation and its functional role in AD patients.

Methods: To assess the Mest promoter methylation, bisulfite sequencing technique was used. CRIPSR/Cas9 system was used to generate the Mest knockout (KO) in both embryonic carcinoma and mouse embryonic stem cells. Lentiviral Split-Cas9 system (LSC-5) was employed to generate inducible Mest KO in neurons.

Results: We found that Mest promoter is hypermethylated, which led to the reduction of Mest mRNA levels and activation of Wnt signaling in the brain tissues of AD patients. Mest KO in both embryonic carcinoma and mouse embryonic stem cells leads to neuronal differentiation arrest. Depletion of Mest in primary hippocampal neurons via lentivirus expressing sh-Mest or inducible KO system caused neurodegeneration. Notably, depletion of Mest in rat primary cortical neurons leads to tau phosphorylation at S199 and T231 sites.

Conclusion: Our study has unfolded the epigenetic modification; Mest promoter hypermethylation in $\mathrm{AD}$. Biochemically, we have linked this with Wnt signaling activation and Tau phosphorylation in neurons.

Keywords: Mest, Hypermethylation, Wnt signaling, Neurodegeneration, Alzheimer's disease. 


\section{Background}

Mis-regulation of $\mathrm{Wnt} / \beta$-catenin signaling is one of the major causes of diseases due to its participation in cell proliferation, self-renewal, and cell fate determination during embryonic development and tissue homeostasis in adult [1]. Consistently, mutations in Wnt signaling components is tightly linked with age-related neurodegenerative conditions, including Alzheimer's disease (AD) [2]. Previous studies have reported the association between LRP6, which is a co-receptor of Wnt ligand, single nucleotide polymorphisms Val 1062 allele and late-onset AD. LRP6 Val 1062 allele shows reduced $\beta$-catenin signaling [3].

Mest is a paternally expressed gene and expressed abundantly in the mesodermal tissue and adult brain $[4,5]$. Imprinting phenomenon refers to the mono-allelic expression of a specific gene due to the only one parent specific methylation of the gene promoter [6]. Mest is expressed only from paternal genome since the maternal gene promoter is methylated. Loss of imprinting (LOI) of Mest is often correlated with altered growth [7]. Mest is a candidate gene for Silver-Russell Syndrome [8], and hypermethylation of Mest promoter is associated with oligozoospermia [9]. In addition, LOI of Mest is also involved in breast, colorectal and lung cancer [10-12]. Genomic imprinting is loosely controlled during aging. Since aberrant Mest hypermethylation and LOI are often associated with various diseases, it is vital to study the functional role and methylation status of Mest promoter in AD patients.

The epigenome-wide association study of AD patients suggests that Mest promoter is potentially hypermethylated in the cortex of $A D$ patients [13]. However, the underlying mechanism on how Mest promoter hypermethylation associated with AD pathology still remain elusive. Herein, we investigated the methylation status of Mest promoter and how it affects Wnt signaling using the brain samples of AD patients and neurons. In the current study, we showed that Mest promoter is hypermethylated in AD patients and the mRNA levels of Mest were reduced while the Wnt target genes were elevated. Mest depletion resulted in 
upregulation of Wnt signaling and tau phosphorylation causing neurodegeneration.

\section{Material and Methods}

\section{Postmortem brain samples}

Frozen postmortem human cortex samples from 9 AD patients and their 9 age-matched controls were used in this study. Neuropathological examination of normal subject and AD human brain samples was determined using procedures previously established by the Boston University Alzheimer's Disease Center (BUADC). Next of kin provided informed consent for participation and brain donation. Institutional review board approval for ethical permission was obtained through the BUADC center. This study was reviewed by the Institutional Review Board of the Boston University School of Medicine (Protocol H-28974) and was approved for exemption because it only included tissues collected from post-mortem subjects not classified as human subjects. The study was performed in accordance with institutional regulatory guidelines and principles of human subject protection in the Declaration of Helsinki. The sample information is listed in Supplementary Table 1 and 2.

\section{DNA extraction and bisulfite conversion}

Total genomic DNA was isolated from postmortem frontal cortex of $A D$ patients using a AccuPrep $\AA$ Genomic DNA Extraction Kit (BIONEER, K-3032) according to the manufacturer's instructions. Each 500ng of genomic DNA was subjected to bisulfite conversion by EZ DNA methylation kit (Zymo Research, D5001) according to the manufacturer's instructions.

\section{Mest promoter amplification and bisulfite sequencing}

The individual genomic DNA was amplified by PCR using the primers indicated in 
Supplementary Table 4. The amplification was done using the following conditions: by $95^{\circ} \mathrm{C}$ for $10 \mathrm{~min}$ followed by 40 cycles $\left(95^{\circ} \mathrm{C}\right.$ for $30 \mathrm{~s}, 55^{\circ} \mathrm{C}$ for $35 \mathrm{~s}$, and $72^{\circ} \mathrm{C}$ for $40 \mathrm{~s}$ and a final extension at $72{ }^{\circ} \mathrm{C}$ for $7 \mathrm{~min}$ ). The PCR products were run on $1 \%$ agarose gels. The PCR products were isolated from the gel slice by Gel extraction kit (ELPIS BIOTECH, EBD-1005). The PCR products were subcloned into pGEM-T easy vector system (Promega, A1360) according to the manufacturer's instructions. The ligation products were transformed into E.coli (DH5a), then spread into LB / ampicillin / IPTG / X-Gal plates. Next day, 12 colonies were picked and amplified / collected plasmid DNA (LaboPass, CMP0112) according to the manufacturer's instructions. The plasmid DNA was sent to DNA sequencing (Bionics). Methylated $\mathrm{CpGs}$ are represented by closed circle, and unmethylated $\mathrm{CpGs}$ are represented by open circle.

\section{Cell culture and transfection}

HEK293FT (Invitrogen) cells were maintained in Dulbecco's modified Eagle medium (DMEM) high glucose containing 10\% fetal bovine serum (FBS), $0.1 \mathrm{mM}$ MEM non-essential amino acids (NEAA), $2 \mathrm{mM} \mathrm{l-glutamine,} 1 \%$ penicillin/streptomycin, and $500 \mu \mathrm{g} / \mathrm{ml}$ Geneticin at $37^{\circ} \mathrm{C}$ with $5 \% \mathrm{CO} 2$ incubation.

Mouse embryonic stem cell E14 cell lines were used for the experiments. mESCs were cultured on a tissue culture dish pre-coated with $0.2 \%$ gelatin (Sigma) at $37^{\circ} \mathrm{C}$ in a $5 \% \mathrm{CO} 2$ incubator. Cell culture media consists of $15 \%$ fetal bovine serum (Bio West), Tylosine (Sigma), $0.1 \mathrm{mM} \beta$-mercaptoethanol (GIBCO), 100X nonessential amino acid (Corning), $1 \mathrm{mM}$ sodium pyruvate (GIBCO), 100X GlutaMAX (GIBCO). LIF-conditioned media was generated by transfection of LIF cDNA to Cos7 cells using Lipofectamine 2000. For subculture, cells were treated with $0.05 \%$ trypsin for $5 \mathrm{~min}$ at $37^{\circ} \mathrm{C}$. After trypsinization, neutralization was done by treatment of FBS containing complete media and centrifuged. Subsequently, mESCs were 
resuspended in culture media and plated on a pre-coated culture dish.

\section{mESC neuronal differentiation}

For neuronal differentiation, $1.0 \times 10^{4}$ undifferentiated mESCs were plated in each well of 6 well plate pre-coated with $0.2 \%$ gelatin. After $24 \mathrm{~h}$, media was replaced with N2B27 media composed of equal amounts of DMEM/F-12 (Welgene) and Neurobasal media (GIBCO) supplemented with N2 (GIBCO) medium, B27 (GIBCO), GlutaMAX (GIBCO), $0.05 \mathrm{mM} \beta$ mercaptoethanol (GIBCO), and 7.5\% BSA (GIBCO). N2B27 media was changed every 2 days.

\section{P19 cell culture and differentiation}

P19 embryonal carcinoma (EC) cells were cultured in Minimum Essential Medium a (MEM $\alpha$, Invitrogen) supplemented with $7.5 \%$ Newborn Calf Serum (NBCS, Gibco) and $2.5 \%$ fetal bovine serum (FBS, Gibco), and 100 units $/ \mathrm{ml}$ penicillin, $100 \mu \mathrm{g} / \mathrm{ml}$ streptomycin, in humidified $5 \% \mathrm{CO}$. To induce P19 EC neuronal differentiation, they were aggregated in bacterial-grade petri dishes with $1 \mu \mathrm{M}$ all-trans-retinoic acid (Sigma) at a density of $1 \times 10^{5} / \mathrm{ml}$. The media was exchanged with fresh media containing retinoic acid after 2 days. After 4 days, aggregates were dissociated by $0.05 \%$ trypsin (Invitrogen), and re-plated in poly-D-lysine and Laminin coated tissue culture dishes and then allowed to differentiate in Neurobasal medium with $2 \%$ B27 supplement, $0.5 \mathrm{mM}$ L-glutamine, $25 \mu \mathrm{M}$ L-Glutamate, and $1 \%$ antibiotics mixture.

\section{Hippocampal primary culture}

Mouse primary hippocampal neuronal cell cultures were prepared from ICR (Young bio, Korea) mice as described (Kim et al., 2011). Experiments were carried as per the standard 
ethical guidelines and were approved by the University of Seoul Institutional Animal Care and Use Committee (UOS IACUC). Briefly, hippocampus was isolated from embryonic day 18.5 mouse embryos using Hank's balanced salts solution. Isolated hippocampus was trypsinized and triturated with fire-polished Pasteur pipettes, then strained through $40-\mu$ m nylon mesh. These cells were cultured in Neurobasal medium with 2\% B27 supplement, $25 \mu \mathrm{M} \mathrm{L-}$ Glutamate, $0.5 \mathrm{mM}$ L-glutamine, and 1\% antibiotics mixture. The same growth media without Glutamate and antibiotics was used for media changes after $4 \mathrm{~d}$. One half of the medium was changed once per week.

\section{Lentivirus preparation and infection}

Lentiviral short hairpin RNA (shRNA) targeting GFP and shRNA targeting Mest was constructed into a lentivirus vector (Invitrogen, BLOCK-iT TM Lentiviral RNAi Expression System, K4944-00). The shRNA sequences are listed in Supplementary Table 3. The shRNA lentivirus was packaged in 293FT cells according to the manufacturer's instructions. Briefly, twenty-four hours prior to transfection, $\sim 5 \times 10^{6}$ HEK293FT cells were seeded on 100-mm tissue culture plates in DMEM high glucose media. Transfections were performed using the Lipofectamine $^{\text {TM }} 2000$ reagent (Invitrogen). The virus-containing medium was centrifuged at $3,000 \mathrm{rpm}$ for $5 \mathrm{~min}$ at $4{ }^{\circ} \mathrm{C}$ to remove cell debris and passed through a sterile $0.45-\mu \mathrm{m}$ filter. The viral supernatant was mixed with PEG-it ${ }^{\mathrm{TM}}$ Virus Precipitation Solution (System Biosciences) and incubated at $4^{\circ} \mathrm{C}$ overnight. After $\mathrm{O} / \mathrm{N}$ incubation, the mixture was centrifuged and the viral pellet was resuspended in phosphate-buffered saline (PBS) and titrated using qPCR Lentivirus Titration Kit (ABM), and virus aliquots were stored at $-80^{\circ} \mathrm{C}$. The enriched lentivirus particle was used for primary hippocampal neuron infection in the presence of $5 \mu \mathrm{g} / \mathrm{ml}$ of polybrene (Sigma-Aldrich). 


\section{Lentiviral transduction and inducible P19 LSC-5 cell generation}

P19 cells were transduced with LSC-5 empty and LSC-5 Mest gRNA lentivirus in media supplemented with $5 \mathrm{ug} / \mathrm{mL}$ polybrene (Sigma). The transduced cells were selected with puromycin (Sigma) for 7 days and the enriched P19 LSC-5 cells were cultured in rapamycin containing media for 5 days. P19 cells were induced with retinoic acid and rapamycin for 4 days in petridish. Retinoic acid induced P19 cells dissociated into single cells and were plated on PDL-laminin coated plate in B27 containing media with rapamycin until 11-day neurons. Rapamycin containing media was changed every $24 \mathrm{~h}$ with fresh media containing $200 \mathrm{nM}$ rapamycin.

\section{Gene knockout using CRISPR-Cas9}

pLKO.1 - TRC was digested with Agel and EcoRI and gel purified to extract the vector fragment. The Mest gRNA cassette was PCR amplified the from template plasmid (PLKOgRNA-Gsk3a) using the primer sequences listed in Supplementary Table 3. The insert ( 200bp) was then ligated to vector using NEB Gibson assembly kit (Catlog \# E5510).

For stable expression of Cas9, E14 and P19 EC cells were co-transfected with PB-CAGhCas9-IRES-hygro and PiggyBac Transposase vector using Lipofectamine 2000(Invitrogen), according to the manufacturer's instructions. The transfected cells were selected with hygromycin for 2 weeks to generate E14-Cas9, and P19 Cas9 cells. To package the pLKO.1Mest gRNA vector, packaging plasmids psPAX2 and VSV-G, were co-transfected into HEK293FT cells using Lipofectamine 2000. After 72 hours, the supernatant was collected and passed through $0.45 \mu \mathrm{m}$ filters. The lentivirus was concentrated using PEG-it ${ }^{\mathrm{TM}}$ Virus Precipitation Solution. The E14 cells and P19 EC Cas9 stable cells were transduced with lentiviral Mest gRNA in the presence of $5 \mu \mathrm{g} / \mathrm{ml}$ polybrene (Sigma) and puromycin selection was done to select colonies with Mest knockout cells. The primer sequences used for T7E1 
primers are listed in Supplementary Table 3.

\section{Immunofluorescence analysis}

The P19 and primary hippocampal neurons were seeded onto poly-D-lysine and Laminin coated glass coverslips in 12-well plates, fixed for 10 min in $4 \%$ paraformaldehyde in PBS, and then permeabilized for 20 min with $0.1 \%$ Triton $\mathrm{X}-100$ in PBS at room temperature. Coverslips were washed once with PBS and blocked with 5\% (wt/vol) bovine serum albumin (Bio basic) in PBS for $2 \mathrm{~h}$, and then incubated with the indicated primary antibodies diluted in $1 \%(\mathrm{wt} / \mathrm{vol}) \mathrm{BSA}$ for overnight in a humidified chamber at $4^{\circ} \mathrm{C}$. Coverslips were then washed three times with PBS and incubated with the secondary antibodies Alexa-Fluor antibodies 488 or 546 (Invitrogen) diluted in 1\% (wt/vol) BSA for 2 h. For nuclei staining, Hoechst 33342 solution or DAPI were added to each sample and incubated at $10 \mathrm{~min}$ at room temperature. Fluorescent images were captured with a confocal microscope (Carl Zeiss LSM 700).

\section{Immunoblotting}

Cell lysates were prepared in buffer composed of RIPA with protease inhibitor cocktail tablets (REF 11836170001) and p-stop (REF 04906837001). Lysates were centrifuged at 13,000 r.p.m for $10 \mathrm{~min}$ at $4^{\circ} \mathrm{C} \min$ to isolate the soluble proteins. Equal amounts of protein were boiled with loading sample buffer (NuPAGE LDS; Invitrogen, Carlsbad, CA, USA) containing $5 \%$ of 2 -mercaptoethanol for 10 minutes and resolved on $10 \%$ SDS-PAGE and transferred to PVDF membrane (Pall). After blocking with $5 \%$ dry milk for $1 \mathrm{~h}$ at room temperature, membranes were incubated overnight at $4^{\circ} \mathrm{C}$ with primary antibodies diluted in $5 \% \mathrm{BSA}$. The following day, the membranes were washed 3 times with Tris buffered saline solution with $0.1 \%$ tween and then incubated with a horseradish peroxidase-coupled secondary antibody (Goat antimouse \#115-035-003 and Goat anti-rabbit \#111-035-003, Jackson 
Immunoresearch Laboratories, West Grove, PA, USA) or Rabbit True Blot antibody (eBioscience, San Diego, USA).

Rabbit monoclonal anti-Mest (\#ab151564), anti-Tau (phospho S199) (\#ab4749), anti-Tau (phospho T231) (\#ab151559), anti-Tau (phospho S396) (\#ab109390), antibodies were obtained from abcam. Mouse monoclonal anti-Vinculin (\#V9131) antibody and anti- $\beta$-actin were obtained from Sigma. Mouse monoclonal Anti-Neuron-specific beta-III Tubulin (\#MAB1195) antibodies were purchased from R\& D systems. Rabbit polyclonal Anti-Cleaved Caspase-3 (Asp175) (\#9661), antibody was obtained from Cell Signaling Technology.

\section{Isolation of mRNA and qPCR analysis}

For quantitative real-time PCR, total RNA was isolated using TRIZOL reagent (Invitrogen) and cDNA synthesis was performed using ImProm-II ${ }^{\mathrm{TM}}$ Reverse Transcriptase (Promega) according to the manufacturer's protocol. Quantitative PCR (qPCR) was carried out by using CFX connect real-time PCR (BIO-RAD) with SYBR Green PCR Master Mix (TOYOBO). The primer sequences used for QPCR are listed in Supplementary Table 4.

\section{Statistical analysis}

All statistical data are expressed as the mean \pm SD and number of sample size $(n=3)$ were indicated in each figure legends. Most of the experiments were repeated three times. The statistical significance of differences between different groups was analyzed using the Student's t-test. P-values were calculated using Student's t-test and the values of ${ }^{*}, p<0.05$; ${ }^{* *}, p<0.01 ;{ }^{* *}, p<0.001{ }^{* * \star *}, p<0.0001$ were considered significant. 


\section{Results}

Hypermethylation of Mest promoter and upregulation of Wnt signaling in brain samples of $A D$ patients

JS Rao and colleagues have reported that frontal cortex from $A D$ patients showed hypermethylation of $\mathrm{CpG}$ islands in BDNF, synaptophysin promoters and increased global DNA methylation [15]. To check whether sporadic AD patients show any differences in CpG methylation in Mest promoter regions, we analysed DNA sample extracted from temporal cortex of postmortem sporadic AD patients and age matched controls. The clinical characteristics of control and AD patients are indicated in Supplementary Tables 1-2. Representative example of methylation pattern of Mest promoter region in DNA extracted from the brain of normal aged subjects showed equal number of clones consisting of methylated and unmethylated alleles (Fig. 1a). Interestingly, $44.4 \%$ of the AD cases showed hypermethylation in Mest promoter in comparison to $11.1 \%$ observed in normal aged (NA) controls (Fig. 1b and c). To show the observed Mest promoter hypermethylation was not a PCR-generated artifact, we examined $\mathrm{H} 19$, another paternally imprinted gene, as a control. We found that $\mathrm{H} 19$ promoter exhibited hypermethylation in $22.2 \%$ of $A D$ cases, indicating that the Mest promoter hypermethylation seen in AD patients is specific to Mest (Fig. 1c and S1A). Another interesting finding is that Mest promoter methylation is tightly controlled in which the clones showed all or none methylation pattern (Fig. 1b), while H19 promoter methylation pattern is loosely controlled in both normal aged and AD cases (Fig. S1A). Our results are consistent with reports that cortex-specific Mest promoter hypermethylation is associated with AD neuropathology [13].

Consistently, the mRNA levels of Mest are downregulated in the temporal cortex of sporadic AD postmortem brains in comparison to normal subjects ( $n=7)$ (Fig. 1d). Canonical Wnt target genes (Axin2, c-Myc) were also upregulated in AD patients, which is consistent 
with the previously reported role of Mest as a negative regulator of Wnt signaling (Fig. 1e and S1B) [15]. These results suggest a potential link between hypermethylation of Mest promoter and elevation of Wnt signaling in AD.

\section{Mest $\mathrm{KO}$ in embryonic carcinoma and embryonic stem cells lead to neuron differentiation blockade}

To assess the functional significance of Mest in neurons, P19 embryonic carcinoma cells were differentiated to neuronal lineage $[16,17]$ and the levels of its mRNA and protein were examined (Fig. S2A-B). The levels of both Mest mRNA and protein were increased during neuronal differentiation (Fig. 2a-b). Next, we generated P19 Mest KO cells using CRISPR/Cas9 system. The presence of indel mutations was confirmed by T7 endonuclease 1 (T7E1) assay and genomic DNA sequencing (Fig. 2c-d). Mest mRNA and protein levels were reduced significantly in KO clone (Fig. 2e-f). P19 Mest KO cells exhibited neuron differentiation arrest with the increased expression of cleaved caspase-3 (Fig. $2 \mathrm{~g}$ ).

We also investigated the role of Mest in the early differentiation of mouse embryonic stem cells (mESCs) by generating Mest KO mESCs. Mest protein and mRNA levels were significantly reduced in Mest KO cells compared to control (Fig. S3A-B). Indel mutations were also observed in Mest KO clones (Fig. S3C). Mest levels were increased during neuronal differentiation, whereas neuronal differentiation marker, Nestin levels were significantly decreased in Mest KO cells (Fig. S3D-E). By using embryonic body (EB) differentiation method, we checked the levels of Mest during differentiation. We found that Mest expression is low in mESCs and increased with differentiation (Fig. S3F). Various lineage-specific markers (Nestin, GSC, GATA4) were significantly impaired during differentiation of Mest KO cells, suggesting that the depletion of Mest affects differentiation potential of mESCs (Fig. S3G-I). 


\section{Mest depletion results in elevation of Wnt signaling and Tau phosphorylation causing neurodegeneration.}

To examine the effect of abnormal $\mathrm{Wnt} / \beta$-catenin signaling levels in neurodegeneration, primary hippocampal neurons of DIV7 were treated with small molecules, which regulate Wnt signaling. XAV939 antagonizes Wnt signaling via stimulation of $\beta$-catenin degradation and stabilization of Axin [18]. Hippocampal neurons treated with XAV939 showed increased apoptosis and neurodegeneration (Fig. S4A-B, A'). These results are consistent with our previous reports that reduced Wnt signaling leads to neurodegeneration by small molecule ICG-001 [19]. The GSK-3 inhibitor, LiCl was used as Wnt signaling activator [20]. Treatment of $\mathrm{LiCl}$ also showed increase of apoptotic cells and neurodegeneration (Fig. S4C-D, B'). Similarly, treatment of either XAV939 or LiCl showed significant reduction of neuronal markers in P19 day 8 neurons (Fig. S4E-F). Consistently, Wnt target genes were downregulated and upregulated in XAV939 and $\mathrm{LiCl}$ treated groups respectively. Overall, either activation or inhibition of Wnt signaling leads to neurodegeneration indicating that Wnt signaling must be in controlled levels for the maintenance of neuronal survival.

Next, in order to mimic the low level of Mest in AD patients, we employed inducible splitCas9 system [21] to suppress endogenous Mest expression. LSC-5 Mest gRNA was constructed and transduced into P19 cells (Fig. S5A-B). Treatment of P19 LSC-5 Mest gRNA stable cells with rapamycin suppressed Mest mRNA expression and increased Wnt target gene levels (Fig. 3a). Mest inducible KO (MiKO) cells also showed reduction of neuronal markers levels. MiKO cells formed large aggregates while control cells exhibited a proper neurite formation (Fig. 3b). Immunofluorescent examination showed that control cells exhibited intact neuron morphology with decent neuronal differentiation upon staining with Tuj1 whereas MiKO cells displayed fragmented neurites with few surviving neurons and with positive signals for cleaved caspase 3 (Fig. 3b). Wnt signaling components such as p-LRP6, 
$\beta$ - catenin, $A B C$ were also increased in MiKO cells (Fig. $3 c$ ). These findings propose that Mest suppression forced the activation of Wnt signaling resulting in neurodegeneration.

To corroborate our findings, primary hippocampal neurons were transduced with shMest lentivirus. The mRNA expression of neuronal markers in Mest knockdown cells were significantly reduced and the expression levels of Wnt target genes were increased (Fig. 3d). Mest knockdown neurons also stained positive for cleaved caspase 3 (CC3) suggesting occurrence of apoptosis, while shGFP treated cells remained intact with the expression of Tuj1 (Fig. 3e). Tau phosphorylation causes formation of neurofibrillary tangles. A gradual increase in Tau phosphorylation at Tyr18, Thr231 and Ser199 sites correlate with AD severity [22]. Interestingly, we found that Mest knockdown in rat cortical neurons increased tau phosphorylation at Ser199 and Thr231 residues (Fig. 3f). Overall, these results demonstrate that Mest suppression results in increased Wnt signaling and tau phosphorylation therefore possibly causing neurodegeneration.

\section{Discussion}

Wnt signaling plays an essential role in neuron maturation, synaptogenesis, axonal remodeling, and long-term potentiation. These processes which are impaired in AD, lending support to the view that Wnt signaling is a possible choice for genetic studies aimed to understand $A D$ pathogenesis [23-25]. The protein level changes were most noticeable in $\beta$ catenin, GSK3 $\beta$, and TCF3 indicative of altered Wnt signaling in AD [26]. In this regard, common genetic variations of LRP6 SNPs, Dishevelled 1 , and GSK3 $\beta$ are found in AD $[3,27$ 29]. Although the mechanisms are not entirely understood, Wnt signaling has both pathogenic and protective role in $A D$ [30]. In rat hippocampal neurons, Wnt3a treatment showed protective function by reducing $A \beta$ toxicity and tau phosphorylation [31]. In contrast, FADlinked PSEN1 mutations (M146L \& M146V) increases $\beta$-catenin levels and Wnt target genes 
expression resulting in pathogenic effects [32, 33]. Our data support the hypothesis that overactivation of Wnt signaling upon Mest depletion caused neurodegeneration of hippocampal neurons (Fig. 3).

$A D$ progression may potentiate pathological changes due to epigenetic regulation. The basis for the methylation changes in $A D$ are still unclear. Studies have shown that promoter region of the APP gene is hypomethylated after 70 years of age, which might result in its aberrant expression, thus generating excessive $A \beta$ [34]. Neprilysin is one of the vital $A \beta$ degrading enzymes in the brain and its promoter is highly methylated resulting in the accumulation of $A \beta$ [35]. Notably, we observed Mest promoter hypermethylation in the patients of $A D$ brain. The current study revealed that the Mest promoter hypermethylation maybe the epigenetic mechanism responsible for the reduction of Mest mRNA levels in AD patients (Fig.1). Our results also corroborates previous reports that Mest promoter is hypermethylated and its mRNA level is decreased significantly in AD brain $[13,36]$. The reasons for the enrichment of hypermethylated alleles in Mest promoter in AD patients is unclear and requires further study. It would be interesting to elucidate the upstream mechanisms which causes the hypermethylation of Mest promoter in the patients of AD brain.

Tau protein is predominantly phosphorylated at Ser/Thr-Pro sites causing formation of neurofibrillary tangles [37]. Tau phosphorylation is highest at Tyr18, Thr231 and Ser199 residues in the cortex and it is correlated with the progression of AD [22]. In the present study, we showed that Mest depletion caused tau hyperphosphorylation at Ser199 and Thr231 sites in rat cortical neurons (Fig. 3f). The microarray studies on AD cortex with neurofibrillary tangles also showed diminished levels of Mest [38]. Finding the tau kinase responsible for tau phosphorylation upon Mest reduction requires further investigation.

The current results should be interpreted with caution, as larger number of AD patient samples should be analyzed. The role of Mest in other signaling pathways is still not clear. 
Within the broader framework of $A D$, our results hint us to speculate that increased Wnt signaling upon reduced expression of Mest due to loss of imprinting may cause neurodegeneration.

\section{Conclusion}

In conclusion, we found that Mest promoter hypermethylation causes the reduction of Mest mRNA levels and activation of Wnt signaling in the brain tissues of AD patients. Mest depletion in primary cultured neurons resulted in upregulation of Wnt signaling and tau phosphorylation causing neurodegeneration. Unfolding the epigenetic modifications; Mest promoter hypermethylation, may provide new insights into the underlying mechanisms that influence neurodegeneration and AD progression.

Supplementary Information accompanies the paper at Molecular Neurodegeneration website

\section{Abbreviations}

AD: Alzheimer's disease; Mest: Mesoderm-Specific Transcript; Peg1; Paternally Expressed Gene 1; mESCs: Mouse Embryonic Stem cells; SNPs: Single Nucleotide Polymorphisms; LOI: Loss of Imprinting; T7E1: T7 Endonuclease 1 assay; LSC-5: Lentiviral Split-Cas9; shRNA: short hairpin RNA.

\section{Declarations}

\section{Acknowledgements}

Authors greatly acknowledge Jho's laboratory member for their fruitful discussions. 


\section{Declarations}

Not applicable.

\section{Author's contributions}

RP, YS, AT carried out cell culture experiments and interpreted data. HJ and SM designed and performed bisulfite sequencing. MS and WS conducted confocal imaging and interpreted data. JL and HR provided mRNA data from normal and Alzheimer's disease brain. RP, HJ, AT and EJ analyzed the data and wrote the paper. HR, HL, and EJ designed and supervised the experiments. All authors read and approved the final manuscript.

\section{Funding}

This study was supported by the National Research Foundation of Korea grants to E. Jho (NRF-2017M3A9B4062421 and 2020R1A2C3013746) and H.R (NRF-2018M3C7A1056894).

\section{Availability of supporting data}

All data generated or analyzed during this study are included in this article and its supplementary information files.

\section{Ethics approval and consent to participate}

Neuropathological examination of normal subject and $A D$ human brain samples was determined using procedures previously established by the Boston University Alzheimer's Disease Center (BUADC). Next of kin provided informed consent for participation and brain donation. Institutional review board approval for ethical permission was obtained through the BUADC center. This study was reviewed by the Institutional Review Board of the Boston University School of Medicine (Protocol H-28974) and was approved for exemption because 
it only included tissues collected from post-mortem subjects not classified as human subjects. The study was performed with informed consent according to protocols approved by Institutional Review Boards of University of Seoul.

\section{Consent for publication}

Not applicable.

\section{Competing interests}

The authors declare no competing interest.

\section{Author information}

${ }^{1}$ Department of Life science, University of Seoul, Seoul, Republic of Korea, 130-743.

${ }^{2}$ Department of Anatomy, Korea University College of Medicine, Seoul, 136-705, Republic of Korea.

${ }^{3}$ Boston University Alzheimer's Disease Center and Department of Neurology, Boston University School of Medicine, Boston, MA 02118, USA. ${ }^{4}$ Center for Neuroscience, Brain Science Institute, Korea Institute of Science and Technology, Seoul, 02792, Republic of Korea. ${ }^{5}$ Department of Psychiatry, Yeouido St. Mary's Hospital, College of Medicine, The Catholic University of Korea, Seoul, Korea. 


\section{References}

1. Clevers $H$ : Wnt/ $\beta$-catenin signaling in development and disease. Cell 2006, 127:469-480.

2. Logan CY, Nusse R: The Wnt signaling pathway in development and disease. Annu Rev Cell Dev Biol 2004, 20:781-810.

3. De Ferrari GV, Papassotiropoulos A, Biechele T, De-Vrieze FW, Avila ME, Major MB, Myers A, Sáez K, Henríquez JP, Zhao A: Common genetic variation within the lowdensity lipoprotein receptor-related protein 6 and late-onset Alzheimer's disease. Proceedings of the National Academy of Sciences 2007, 104:9434-9439.

4. Lefebvre L, Viville S, Barton SC, Ishino F, Keverne EB, Surani MA: Abnormal maternal behaviour and growth retardation associated with loss of the imprinted gene Mest. Nature genetics 1998, 20:163.

5. Sado T, Nakajima N, Tada M, Takagi N: A Novel Mesoderm-Specific cDNA Isolated from a Mouse Embryonal Carcinoma Cell Line: (embryonal carcinoma cell/cDNA/in situ hybridization/mesoderm/mouse embryo). Development, growth \& differentiation 1993, 35:551-560.

6. Reik W, Walter J: Genomic imprinting: parental influence on the genome. Nature Reviews Genetics 2001, 2:21.

7. Shi W, Lefebvre L, Yu Y, Otto S, Krella A, Orth A, Fundele R: Loss-of-imprinting of Peg1 in mouse interspecies hybrids is correlated with altered growth. genesis 2004, 39:65-72.

8. Kagami M, Nagai T, Fukami M, Yamazawa K, Ogata T: Silver-Russell syndrome in a girl born after in vitro fertilization: partial hypermethylation at the differentially methylated region of PEG1/MEST. Journal of assisted reproduction and genetics 2007, 24:131-136.

9. Marques C, Costa P, Vaz B, Carvalho F, Fernandes S, Barros A, Sousa M: Abnormal methylation of imprinted genes in human sperm is associated with oligozoospermia. MHR-Basic Science of Reproductive Medicine 2008, 14:67-74.

10. Nakanishi H, Suda T, Katoh M, Watanabe A, Igishi T, Kodani M, Matsumoto S, Nakamoto M, Shigeoka Y, Okabe T: Loss of imprinting of PEG1/MEST in lung cancer cell lines. Oncology reports 2004, 12:1273-1278.

11. Pedersen IS, Dervan PA, Broderick D, Harrison M, Miller N, Delany E, O'Shea D, Costello P, McGoldrick A, Keating G: Frequent loss of imprinting of PEG1/MEST in invasive breast cancer. Cancer research 1999, 59:5449-5451.

12. Nishihara S, Hayashida T, Mitsuya K, Schulz T, Ikeguchi M, Kaibara N, Oshimura M: Multipoint imprinting analysis in sporadic colorectal cancers with and without microsatellite instability. International journal of oncology 2000, 17:317-339.

13. Lunnon K, Smith R, Hannon E, De Jager PL, Srivastava G, Volta M, Troakes C, AlSarraj S, Burrage J, Macdonald R: Methylomic profiling implicates cortical deregulation of ANK1 in Alzheimer's disease. Nature neuroscience 2014, 17:11641170.

14. Rao J, Keleshian V, Klein S, Rapoport S: Epigenetic modifications in frontal cortex from Alzheimer's disease and bipolar disorder patients. Translational psychiatry 2012, 2:e132.

15. Jung H, Lee SK, Jho E-h: Mest/Peg1 inhibits Wnt signalling through regulation of LRP6 glycosylation. Biochemical Journal 2011, 436:263-269.

16. McBurney M: P19 embryonal carcinoma cells. International Journal of Developmental Biology 2003, 37:135-140.

17. McBurney MW, Jones-Villeneuve E, Edwards M, Anderson P: Control of muscle and 
neuronal differentiation in a cultured embryonal carcinoma cell line. Nature 1982, 299:165.

18. Huang S-MA, Mishina YM, Liu S, Cheung A, Stegmeier F, Michaud GA, Charlat O, Wiellette $E$, Zhang $Y$, Wiessner $S$ : Tankyrase inhibition stabilizes axin and antagonizes Wnt signalling. Nature 2009, 461:614.

19. Kim H, Won S, Hwang DY, Lee J-s, Kim M, Kim R, Kim W, Cha B, Kim T, Kim D: Downregulation of Wnt/ $\beta$-catenin signaling causes degeneration of hippocampal neurons in vivo. Neurobiology of aging 2011, 32:2316. e2311-2316. e2315.

20. Wu D, Pan W: GSK3: a multifaceted kinase in Wnt signaling. Trends in biochemical sciences 2010, 35:161-168.

21. Zetsche B, Volz SE, Zhang F: A split-Cas9 architecture for inducible genome editing and transcription modulation. Nature biotechnology 2015, 33:139.

22. Neddens J, Temmel M, Flunkert S, Kerschbaumer B, Hoeller C, Loeffler T, Niederkofler V, Daum G, Attems J, Hutter-Paier B: Phosphorylation of different tau sites during progression of Alzheimer's disease. Acta neuropathologica communications 2018, 6:52.

23. Rosso SB, Inestrosa NC: WNT signaling in neuronal maturation and synaptogenesis. Frontiers in cellular neuroscience 2013, 7:103.

24. Purro SA, Ciani L, Hoyos-Flight M, Stamatakou E, Siomou E, Salinas PC: Wnt regulates axon behavior through changes in microtubule growth directionality: a new role for adenomatous polyposis coli. Journal of Neuroscience 2008, 28:8644-8654.

25. Chen J, Park CS, Tang S-J: Activity-dependent synaptic Wnt release regulates hippocampal Iong term potentiation. Journal of Biological Chemistry 2006, 281:11910-11916.

26. Riise J, Plath N, Pakkenberg B, Parachikova A: Aberrant Wnt signaling pathway in medial temporal lobe structures of Alzheimer's disease. Journal of neural transmission 2015, 122:1303-1318.

27. Mateo I, Infante J, Llorca J, Rodríguez E, Berciano J, Combarros O: Association between glycogen synthase kinase-3 $\beta$ genetic polymorphism and late-onset Alzheimer's disease. Dementia and geriatric cognitive disorders 2006, 21:228-232.

28. Russ $\mathrm{C}$, Lovestone $\mathrm{S}$, Powell $\mathrm{J}$ : Identification of sequence variants and analysis of the role of the glycogen synthase kinase $3 \boldsymbol{\beta}$ gene and promoter in late onset Alzheimer's disease. Molecular psychiatry 2001, 6:320.

29. Russ C, Lovestone S, Powell J: Identification of genomic organisation, sequence variants and analysis of the role of the human dishevelled 1 gene in late onset Alzheimer's disease. Molecular psychiatry 2002, 7:104.

30. Boonen RA, van Tijn P, Zivkovic D: Wnt signaling in Alzheimer's disease: up or down, that is the question. Ageing research reviews 2009, 8:71-82.

31. Alvarez AR, Godoy JA, Mullendorff K, Olivares GH, Bronfman M, Inestrosa NC: Wnt3a overcomes $\beta$-amyloid toxicity in rat hippocampal neurons. Experimental cell research 2004, 297:186-196.

32. Malik B, Currais A, Andres A, Towlson C, Pitsi D, Nunes A, Niblock M, Cooper J, Hortobágyi T, Soriano $S$ : Loss of neuronal cell cycle control as a mechanism of neurodegeneration in the presenilin-1 Alzheimer's disease brain. Cell Cycle 2008, 7:637-646.

33. Kang DE, Soriano S, Frosch MP, Collins T, Naruse S, Sisodia SS, Leibowitz G, Levine $\mathrm{F}$, Koo EH: Presenilin 1 facilitates the constitutive turnover of $\beta$-catenin: differential activity of Alzheimer's disease-linked PS1 mutants in the $\beta$-catenin- 
signaling pathway. Journal of Neuroscience 1999, 19:4229-4237.

34. Marques SC, Oliveira CR, Pereira CM, Outeiro TF: Epigenetics in neurodegeneration: a new layer of complexity. Progress in NeuroPsychopharmacology and Biological Psychiatry 2011, 35:348-355.

35. Chen K-L, Wang SS-S, Yang Y-Y, Yuan R-Y, Chen R-M, Hu C-J: The epigenetic effects of amyloid- $\beta 1-40$ on global DNA and neprilysin genes in murine cerebral endothelial cells. Biochemical and biophysical research communications 2009, 378:57-61.

36. Moradifard S, Hoseinbeyki M, Ganji SM, Minuchehr Z: Analysis of microRNA and gene expression profiles in Alzheimer's disease: a meta-analysis approach. Scientific reports 2018, 8:1-17.

37. Johnson GV, Stoothoff WH: Tau phosphorylation in neuronal cell function and dysfunction. Journal of cell science 2004, 117:5721-5729.

38. Dunckley T, Beach TG, Ramsey KE, Grover A, Mastroeni D, Walker DG, LaFleur BJ, Coon KD, Brown KM, Caselli R: Gene expression correlates of neurofibrillary tangles in Alzheimer's disease. Neurobiology of aging 2006, 27:1359-1371. 


\section{Supplementary Figure legends}

\section{Supplementary Figure 1. H19 Promoter methylation and Wnt target gene expression in}

AD brain samples.

A. Methylation profile of H19 promoter in normal aged and AD brain sample. DNA from brain samples from at least 9 subjects from normal aged (NA) and AD subjects were analyzed. There are $23 \mathrm{CpG}$ sites in each row. Each row of circles represents a single cloned allele with at least 12 clones sequenced per subject. The \% methylation is summarized in Fig. $2 \mathrm{~b}$. B. Figure represents mRNA expression of Wnt target genes of individual normal aged vs AD subjects. Target mRNA levels were normalized to $\beta$-actin. Data shown as mean $\pm S D ;{ }^{*}, p$ $<.05 ;{ }^{* *}, \mathrm{p}<.01 ;{ }^{* * *}, \mathrm{p}<.001{ }^{* * * *}, \mathrm{p}<.0001$ compared with the corresponding control group. Student's $t$ test was used for statistical analysis.

\section{Supplemental Figure 2. Increased expression of Mest during neuronal differentiation of P19 cells.}

A. Scheme of P19 neuronal differentiation. UD; undifferentiated, EB; Embryonic body, 8dN; 8 day neuron, RA; Retinoic acid. B. qPCR analyses for Tuj1, MAP2 and Neun mRNA expression during neuronal differentiation. mRNA levels were normalized to $\beta$-actin. Data shown as mean $\pm \mathrm{SD} ;{ }^{*}, \mathrm{p}<.05 ;{ }^{* *}, \mathrm{p}<.01 ;{ }^{* * *}, \mathrm{p}<.001 ;{ }^{* * * *}, \mathrm{p}<.0001$ compared with the corresponding control group. Student's $t$ test was used for statistical analysis.

\section{Supplemental Figure 3. Mest KO in E14 mESCs leads to delayed differentiation.}

A. Mest mRNA expression analysis by RT-PCR in E14 mESC cells transduced with Mest gRNA. The clone 2 showed the absence of Mest transcripts. B. Protein levels of Mest in clone 2. The protein lysates were extracted from clone 2 and Cas 9 (control). Mest expression levels were analyzed by western blot. C. Representative Sanger sequencing trace of one 
Mest targeted clone showing deletion within the Mest coding exon 2 in E14 mESCs. D. Mest mRNA levels were increased in control cells but not in Mest KO cells. The qPCR analysis for Mest mRNA expression during mESC differentiation in N2B27 media. E. Nestin mRNA expression levels were reduced in Mest KO cells upon neuron differentiation in N2B27 media. F. Mest mRNA expression was absent in Mest $\mathrm{KO}$ cells while the control cells showed increased mRNA expression of Mest in embryonic body differentiation. G-I. The mRNA expression of ectodermal (Nestin), mesodermal (GSC), and endodermal (GATA4) markers were reduced in Mest KO cells. mRNA levels were normalized to $\beta$-actin. Data shown as mean $\pm \mathrm{SD} ;{ }^{*}, \mathrm{p}<.05 ;^{* *}, \mathrm{p}<.01 ;{ }^{* * *}, \mathrm{p}<.001 ;{ }^{* * * *}, \mathrm{p}<.0001$ compared with the corresponding control group. Student's $t$ test was used for statistical analysis.

\section{Supplemental Figure 4. Either extremes of Wnt signaling causes neurodegeneration in} neurons.

A-D; Mouse primary hippocampal neurons cultured in vitro for 7 days were incubated with the small molecules indicated in the figure for 48 hours and then immunostained with antiTuj1 (green) and Cleaved Caspase-3 ((CC-3), (red)) antibodies. DMSO, $5 \mu \mathrm{M}$ XAV939; 10 mM Nacl,10 mM LiCl. A'-B'; To determine the percentage of Tuj ${ }^{+}$and cleaved caspase$3(\mathrm{CC}-3)^{+}$cells, the number of Tuj $1^{+} \& \mathrm{CC}-3^{+}$cells was divided by the number of hoechst ${ }^{+}$cells in four randomly selected areas for each sample. Scale bars, $25 \mu \mathrm{m}$. For each sample, more than $150 \mathrm{DAPI}+$ cells were counted. Data are expressed as the means \pm SEM from the indicated number of samples. E-F; The P19 8 day differentiated neurons were treated with the small molecules indicated in the figure for 48 hours and harvested for qPCR analysis. DMSO, XAV939 (5 $\mu \mathrm{M}) ; 10 \mathrm{mM} \mathrm{Nacl}, 10 \mathrm{mM} \mathrm{LiCl}$. mRNA levels were normalized to $\beta$-actin. Data shown as mean $\pm \mathrm{SD} ;{ }^{*}, \mathrm{p}<.05 ;{ }^{* *}, \mathrm{p}<.01 ;{ }^{* * *}, \mathrm{p}<.001 ;{ }^{* * *}, \mathrm{p}<.0001$ compared with the corresponding control group. Student's $t$ test was used for statistical analysis. 


\section{Supplemental Figure 5. P19 LSC-5 stable cell generation and validation}

A. Linear map of lentiviral split-Cas9 plasmid containing U6 promoter-driven Mest gRNA. B. LSC-5 control and Mest-gRNA lentivirus was transduced into P19 cells and selected with puromycin. LSC-5 control and Mest gRNA P19 stable cells were validated for the expression of LSC-5 vector component FRB by qPCR. P19 LSC-5 control and Mest gRNA cells were selected for rapamycin inducible Mest KO.

Supplemental Table 1. Clinical characteristics of the non-demented control subjects in the study

Supplemental Table 2. Clinical characteristics of the Alzheimer's disease subjects in the study

Supplemental Table 3. Sequences for gRNA, shRNA and T7E1 assay Supplemental Table 4. Primers used for qPCR, Mest promoter amplification 


\section{Figure legends}

Figure 1. Hypermethylation of Mest promoter and upregulation of Wnt signaling in brain samples of $A D$ patients.

A. Representative example of cytosine methylation pattern of Mest promoter region in DNA extracted from the brain of normal aged subjects. Each row of circles represents a single cloned allele with at least 12 clones sequenced per subject. The white circles represent nonmethylated $\mathrm{CpG}$ site and black circles for methylated cytosines. There are $29 \mathrm{CpG}$ sites in each row. B. Comparison of $\mathrm{CpG}$ methylation patterns within the Mest promoter in DNA isolated from the cortex of normal aged $(N A)(n=9)$ and $A D$ subjects $(n=9)$ show elevated hypermethylation alleles in AD subjects. C. The summary of Mest and H19 promoter methylation in normal aged (NA) $(n=9)$ and $A D(n=9)$ subjects. D. The mRNA levels of Mest is decreased in AD patients. Amplification plot (red line) analysis showed a delayed in SYBR Green signal, indicating a decrease of Mest expression in the AD patient as compared to the normal control (blue line). The mRNA of Mest is downregulated in the temporal cortex of sporadic AD postmortem brains $(n=7)$ in comparison to normal subjects $(n=7)$. GAPDH was used for normalizing Mest expression. *, Significantly different from the control at $p<0.01$. E. The mRNA levels of Wnt target genes Axin2 and c-Myc were increased in AD subjects $(n=6)$. mRNA levels were normalized to $\beta$-actin. Data shown as mean $\pm \mathrm{SD} ;{ }^{*}, p<.05 ;{ }^{* *}, p<.01$; ${ }^{* * *}, p<.001$ compared with the corresponding control group. Student's $t$ test was used for statistical analysis.

Figure 2. Mest KO in P19 embryonic carcinoma leads to neuron differentiation blockade.

A. $\mathrm{qPCR}$ analyses for Mest mRNA expression during neuronal differentiation. Total RNAs were isolated at the indicated times. B. Mest protein levels in retinoic acid induced P19 
neuronal differentiation. C. T7E1 assay for P19 Mest KO cells. PCR products are generated from the genomic DNA of P19 Mest knockout cells. The PCR products are annealed \& digested with T7 Endonuclease I. Fragments are analyzed to determine the efficiency of genome targeting. D. The P19 Mest KO cells showed 5 base pair deletion near gRNA targeted site upon Sanger sequencing. E. qPCR analyses for Mest mRNA expression in P19 Mest KO cells. F. Mest protein levels in P19 Cas9 and Mest KO cells. G. Mest KO caused neuron differentiation blockade in P19 cells. P19 differentiated neurons were fixed and immunostained with anti-Tuj1 (red) and cleaved caspase-3 ((CC-3), (green)) antibodies at indicated times. Scale bars, $10 \mu \mathrm{m}$. mRNA levels were normalized to $\beta$-actin. Data shown as mean $\pm S D ;{ }^{* * *}, p<.001$; compared with the corresponding control group. Student's t test was used for statistical analysis.

Figure 3. Mest depletion results in elevation of Wnt signaling and Tau phosphorylation causing neurodegeneration.

A. Relative mRNA expression for Mest, neuronal markers and Wnt target genes in 11day neurons of P19 LSC-5 control and Mest gRNA stable cells treated with rapamycin. B. Inducible knockout of Mest caused the neurodegeneration in P19 Mest gRNA stable cells. P19 LSC-5 neurons treated with rapamycin were fixed and immunostained with anti-Tuj1 (green) and cleaved caspase-3 ((CC-3), (red)) antibodies. Phase contrast (top panels, scale bars, $100 \mu \mathrm{m}$ ) and fluorescent images (bottom panels) of 11day neurons of P19 LSC-5 control and Mest gRNA stable cells induced with rapamycin. Scale bars, $88 \mu \mathrm{m}$. C. Deficiency of Mest leads to increased Wnt signaling. Western blotting for Mest, and Wnt signaling components LRP6, p-LRP6, $\beta$-catenin, Active $\beta$ catenin $(A B C)$ in P19 Mest inducible KO cells isolated from (B) was performed. Vinculin was used as a loading control. Filled arrow indicates specific band. D. qPCR analysis for Mest, neuronal markers and Wnt target genes in DIV7 
hippocampal neurons infected with lentiviral shMest. E. Mest knockdown caused the neurodegeneration in hippocampal neurons. DIV7 hippocampal neurons treated with lentishMest were immunostained with anti-Tuj1 (green) and cleaved caspase-3 ((CC-3), (red)) antibodies. Scale bars, $18 \mu \mathrm{m}$. F. DIV7 rat hippocampal neurons treated with shMest lentivirus showed increase of tau phosphorylation at S199, and Thr231 sites. All mRNA levels were normalized to $\beta$-actin. Data shown as mean $\pm \mathrm{SD} ;{ }^{*}, \mathrm{p}<.05 ;{ }^{* *}, \mathrm{p}<.01 ;{ }^{* * *}, \mathrm{p}<.001 ;{ }^{* * * *}, \mathrm{p}$ $<.0001$ compared with the corresponding control group. Student's $t$ test was used for statistical analysis. 


\section{Figure 1}

A

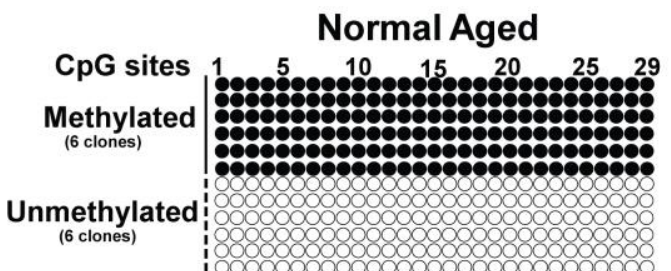

B

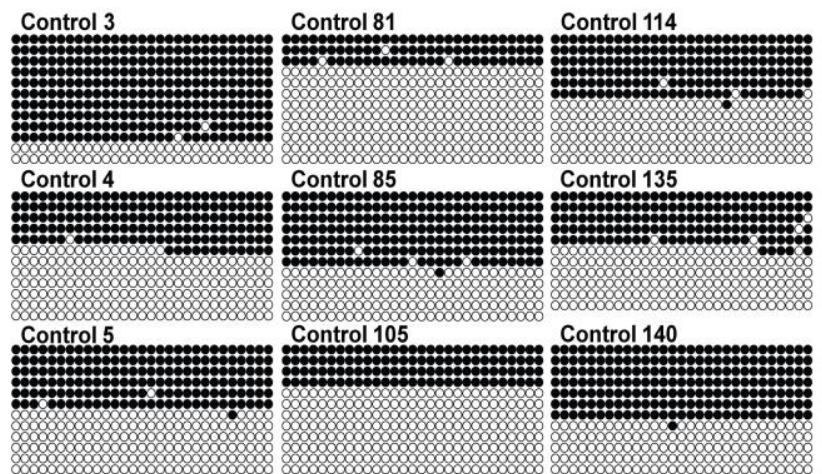

D

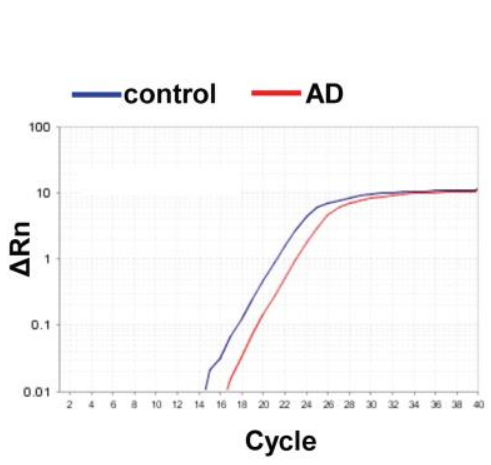

C

\begin{tabular}{cccc}
\hline Gene & Methylation & $\begin{array}{c}\text { AD } \\
(n=9)\end{array}$ & $\begin{array}{c}\text { NA } \\
(n=9)\end{array}$ \\
\hline \multirow{2}{*}{ Mest } & Hyper & $44.4 \%$ & $11.1 \%$ \\
& Hypo & $22.2 \%$ & $11.1 \%$ \\
H19 & Hyper & $22.2 \%$ & $0 \%$ \\
& Hypo & $33.3 \%$ & $22.2 \%$ \\
\hline
\end{tabular}

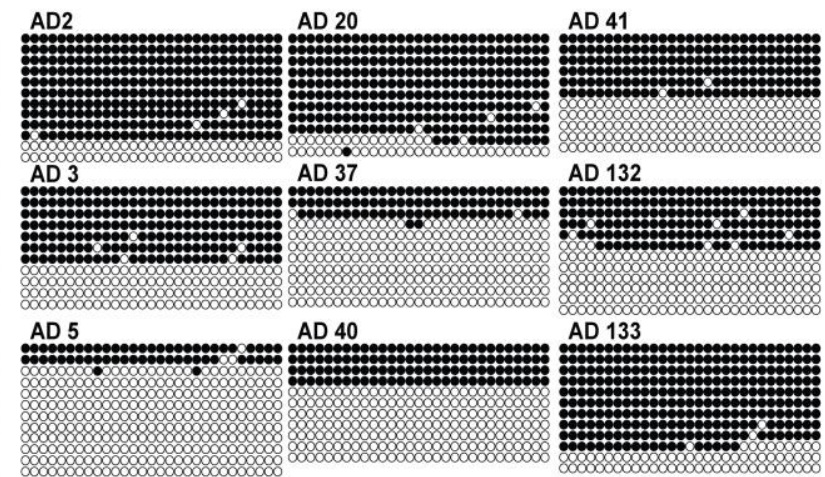

E

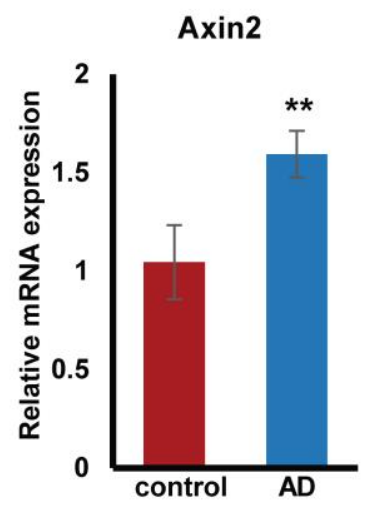

c-Myc

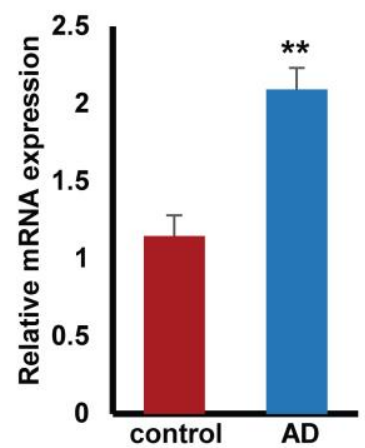




\section{Figure 2}

A

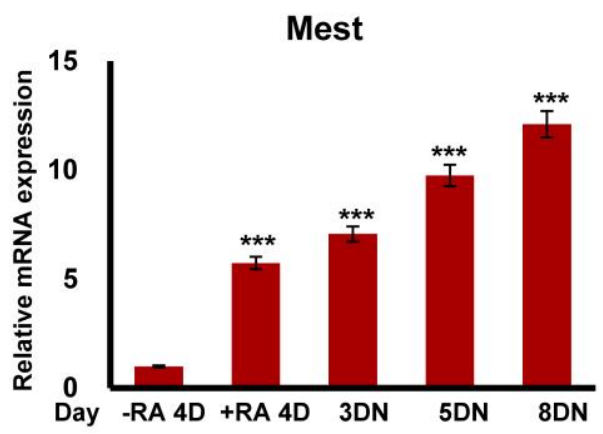

C

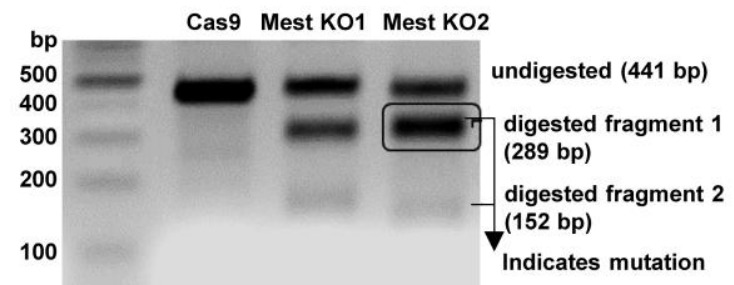

D

P19 cells

Mest_-

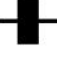

Ref CATTTTCCTCCTAGATTCTGTCGGTGTOGTCGGAAGCI

WT CATTTTCCTCCTAGATTCTGTCGGTGTGGTGGAAGC

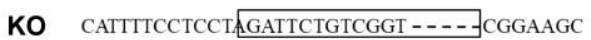

E

$\mathbf{F}$

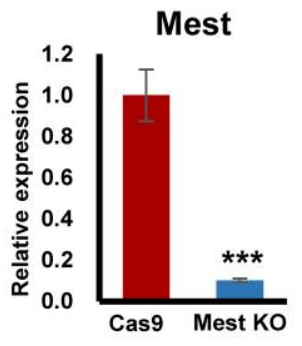

B

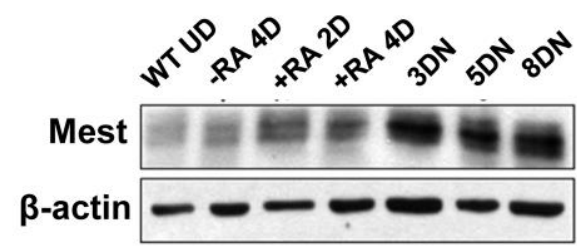

G

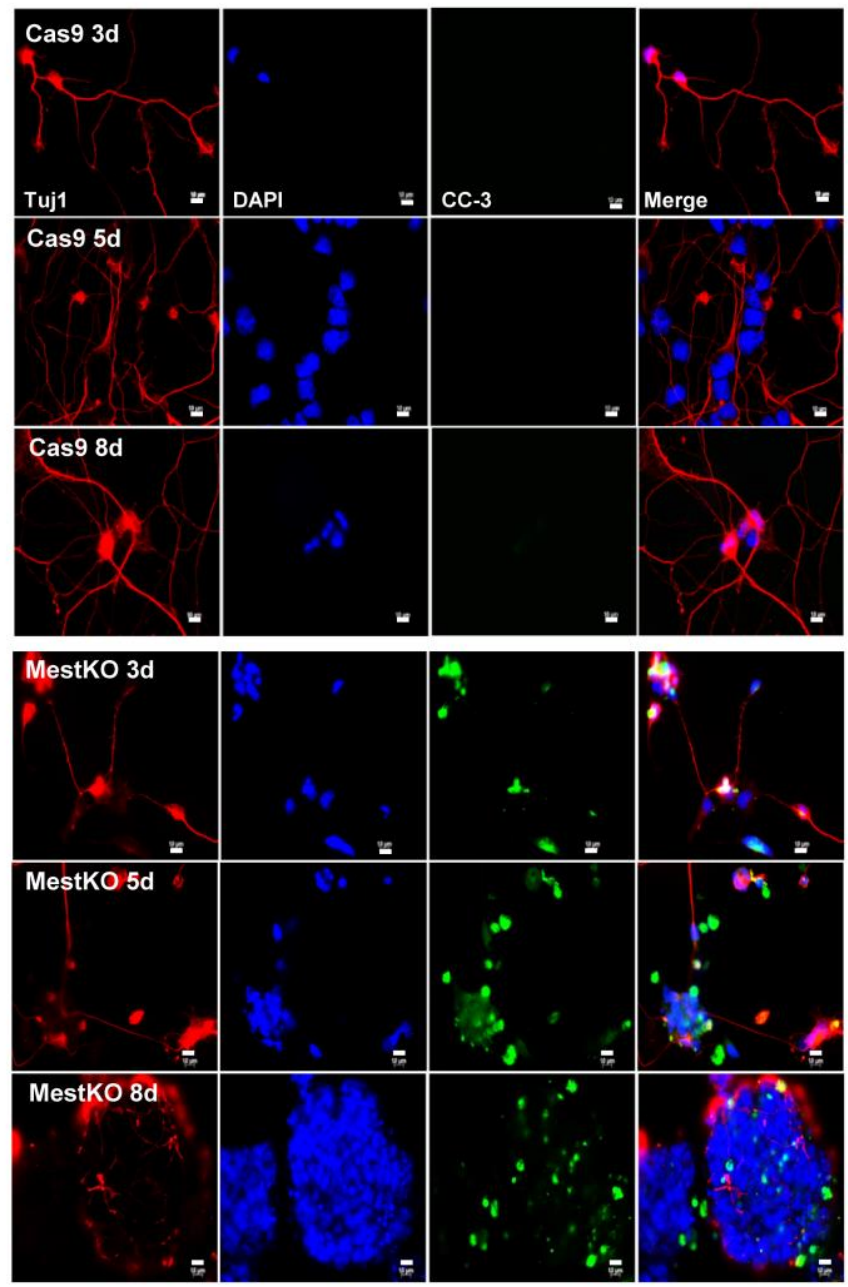




\section{Figure 3}

A
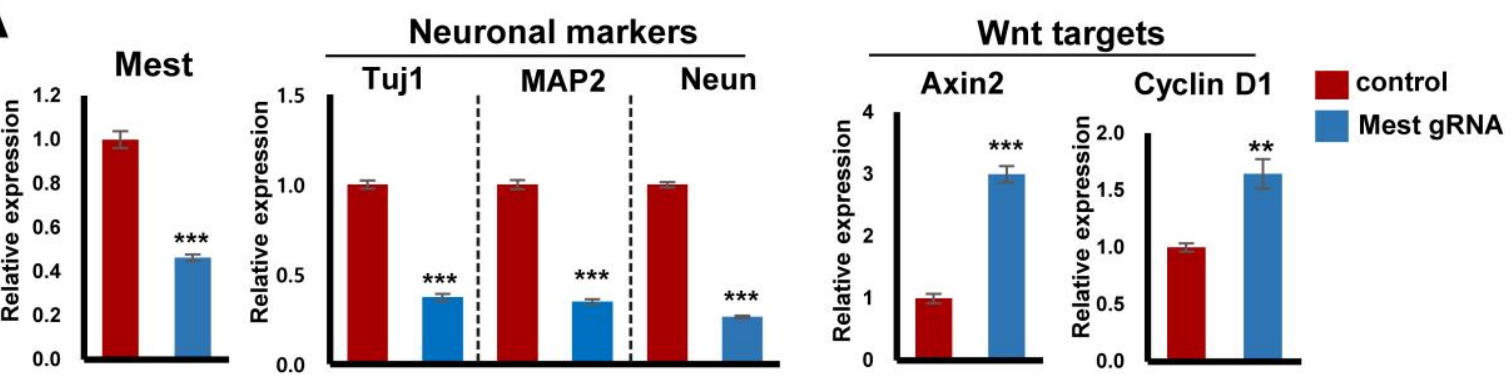

B

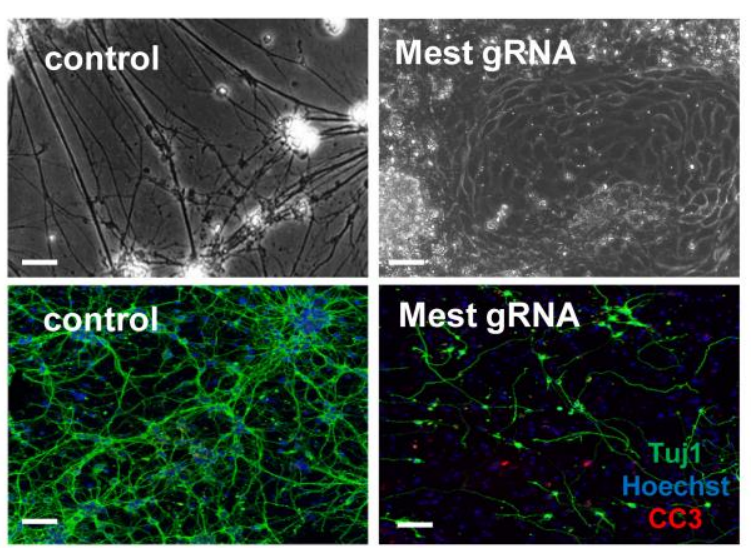

C

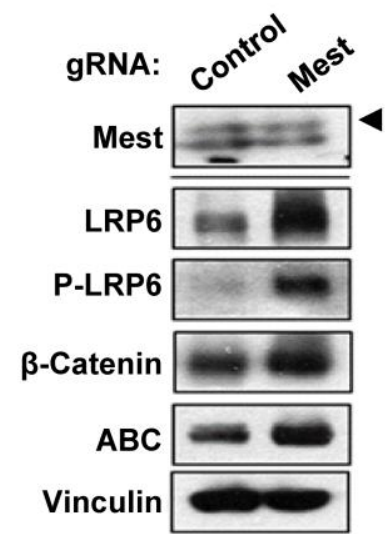

D
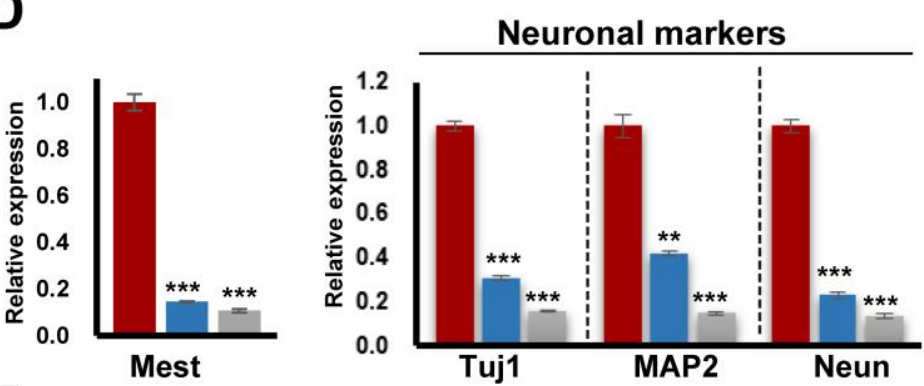

E
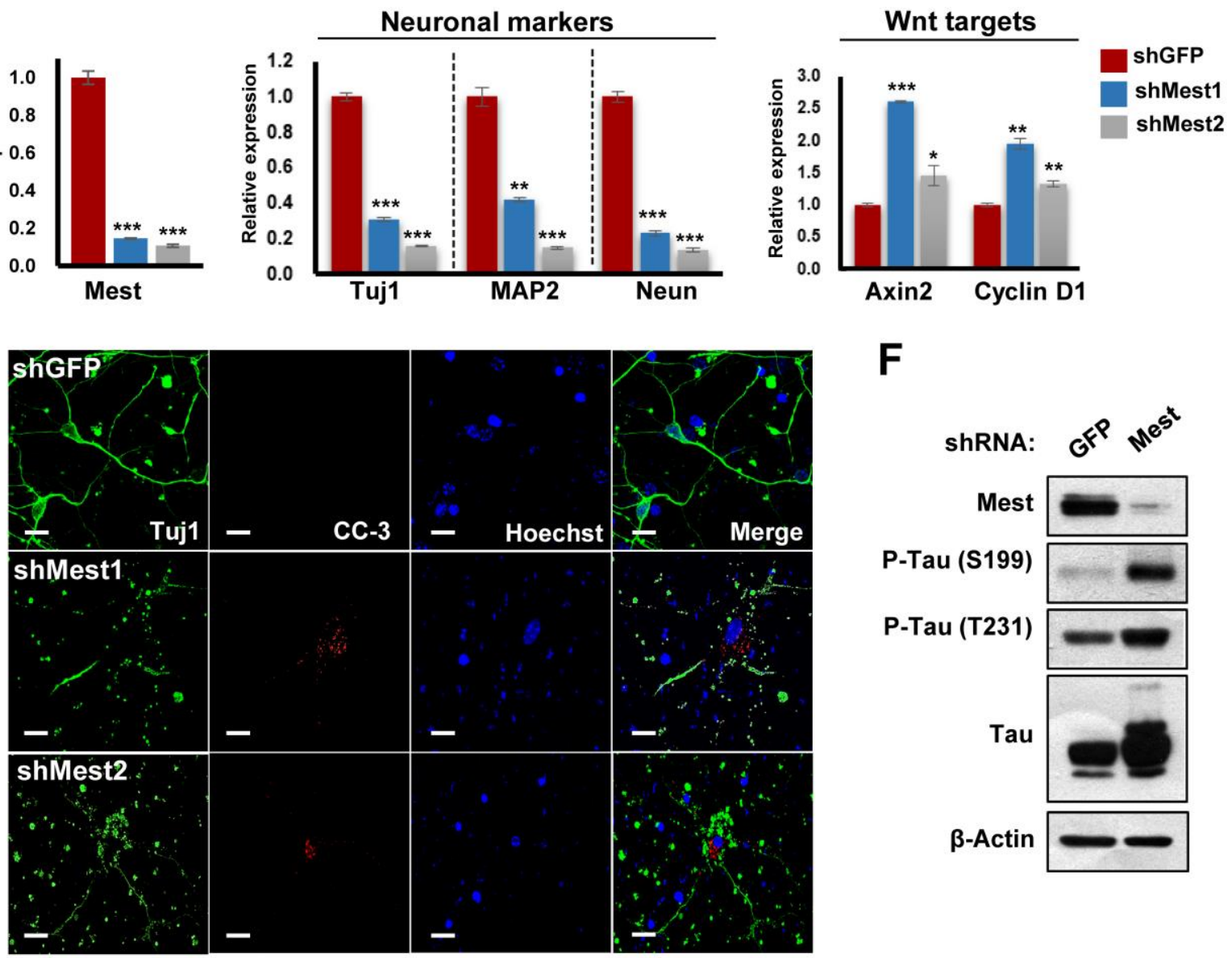

F

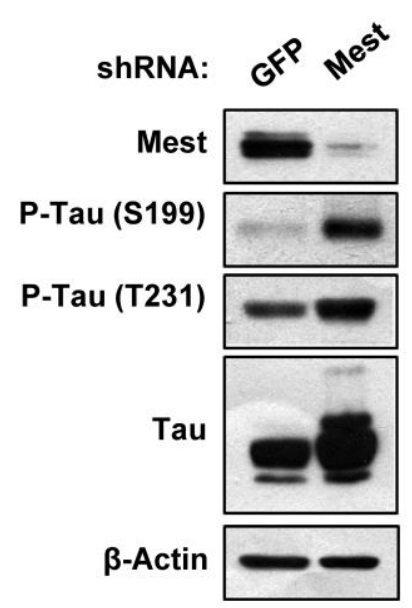




\section{Supplemental Figure 1 (Related to Figure 1)}

A

H19 CpG methylation of NA brain sample
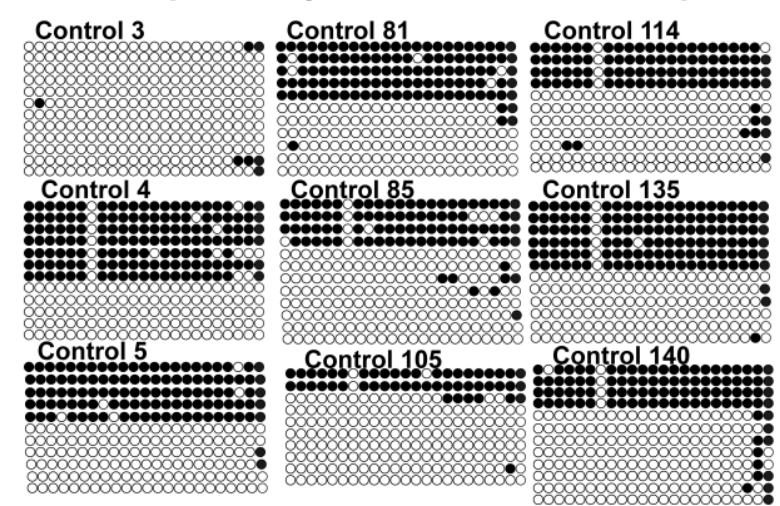

H19 CpG methylation of AD brain sample

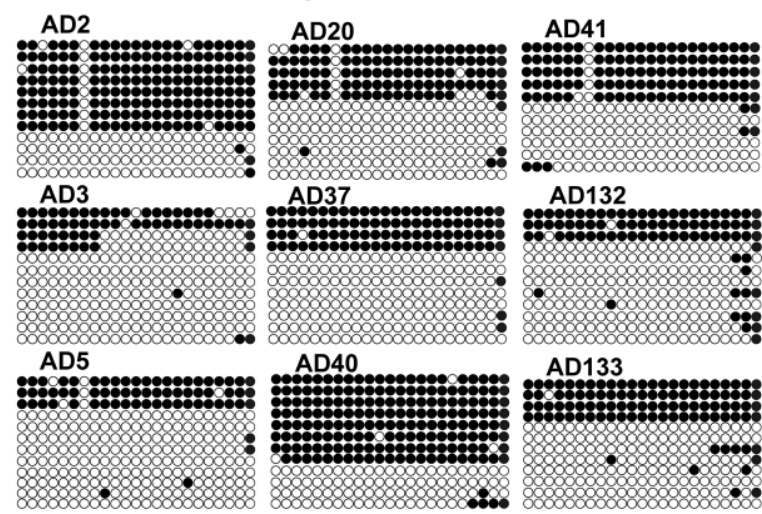

B

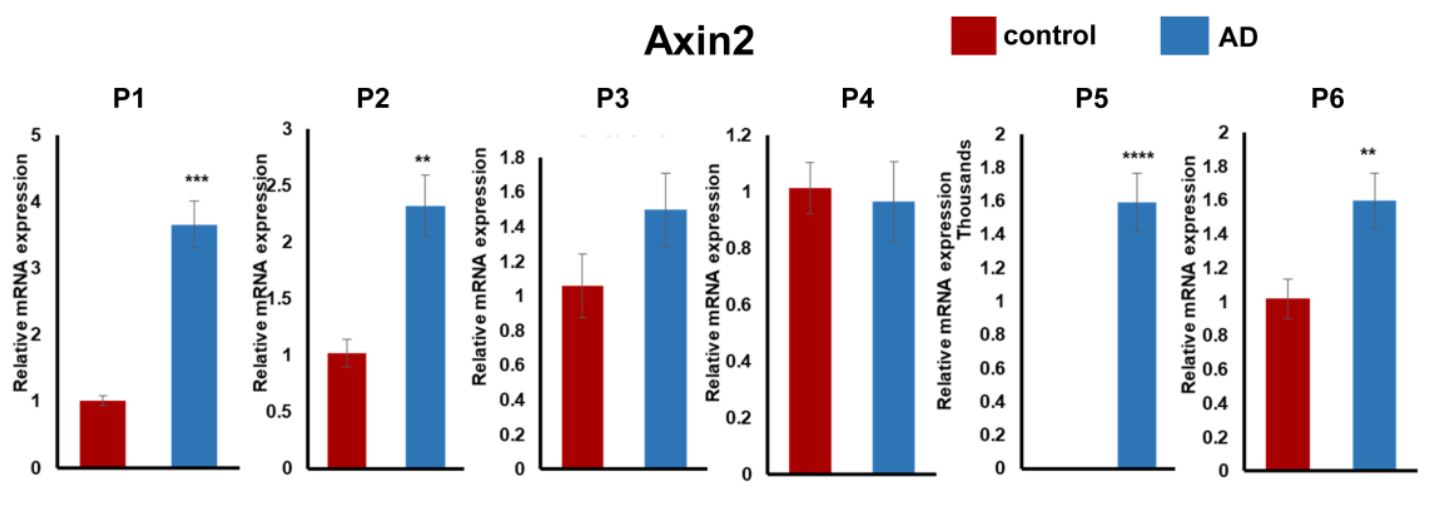

P1

P2

C-Myc
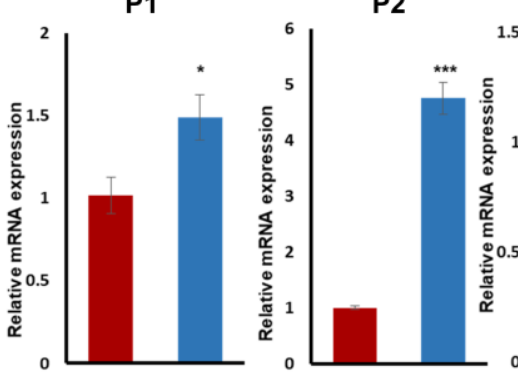

P3

P4

P5

P6
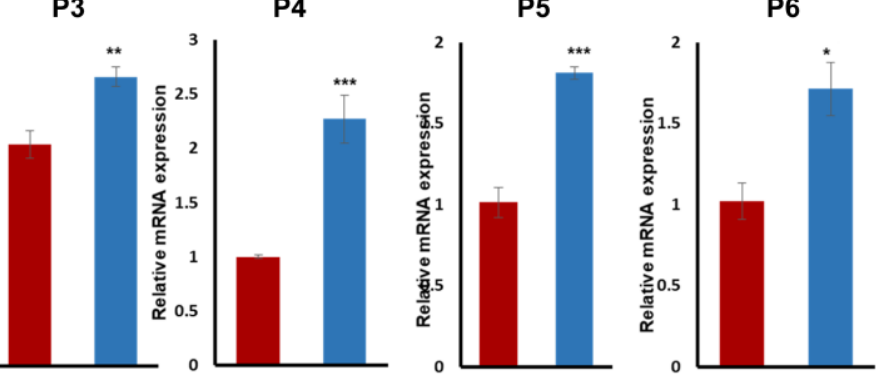


\section{Supplemental Figure 2 (Related to Figure 2)}

A

P19 cells

\begin{tabular}{|c|c|c|c|c|c|}
\hline \multicolumn{3}{|c|}{ Programming stage } & \multicolumn{3}{|c|}{ Differentiation stage } \\
\hline & $\overline{\text { nsion Cultu }}$ & $(1 \mu \mathrm{M})$ & & rent Culture+ B27-N & \\
\hline Od & Petri dish & $4 d$ & $0 \mathrm{dN}$ & PDL-laminin plate & $8 \mathrm{dN}$ \\
\hline
\end{tabular}

B

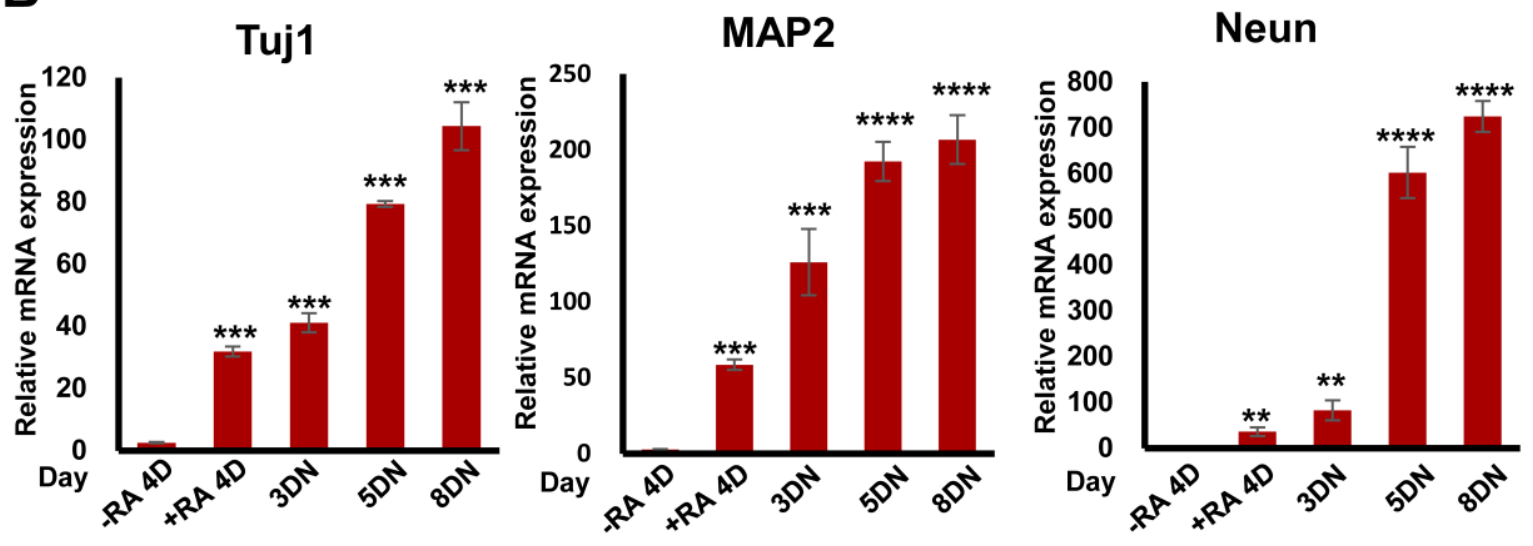




\section{Supplementary Figure 3 (Related to Figure 2)}

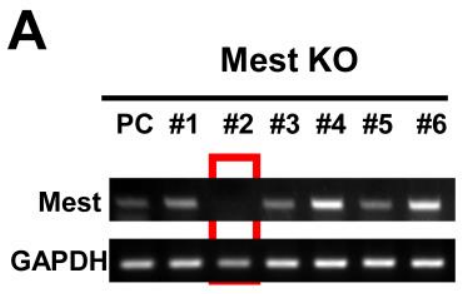

D

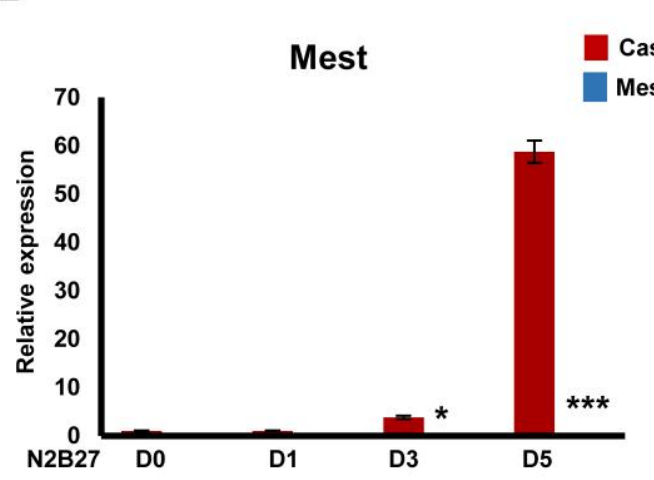

C

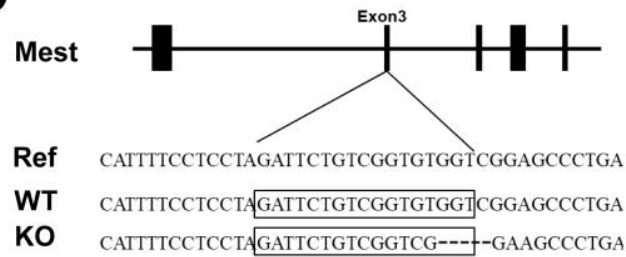

E

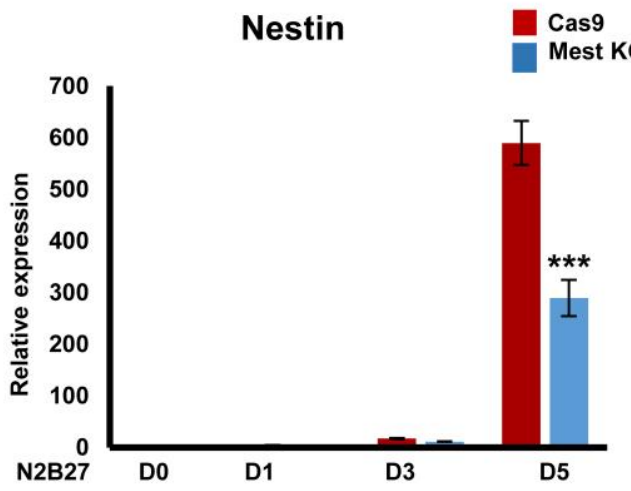

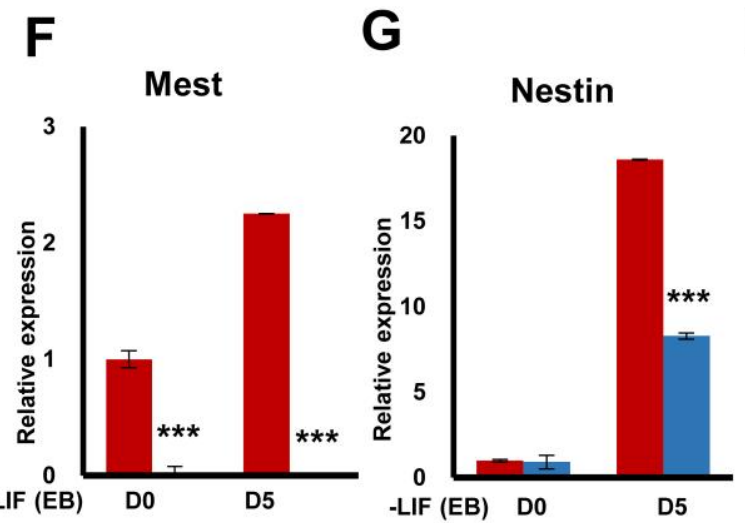

H

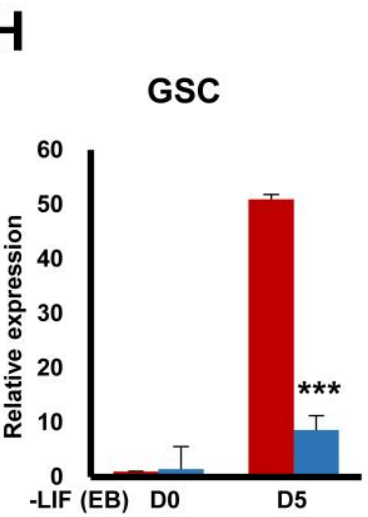

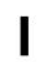

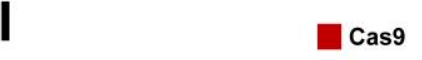

GATA4 Mest Ko

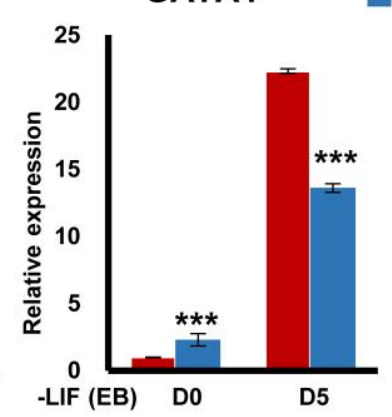


Supplemental Figure 4 (Related to Figure 3)

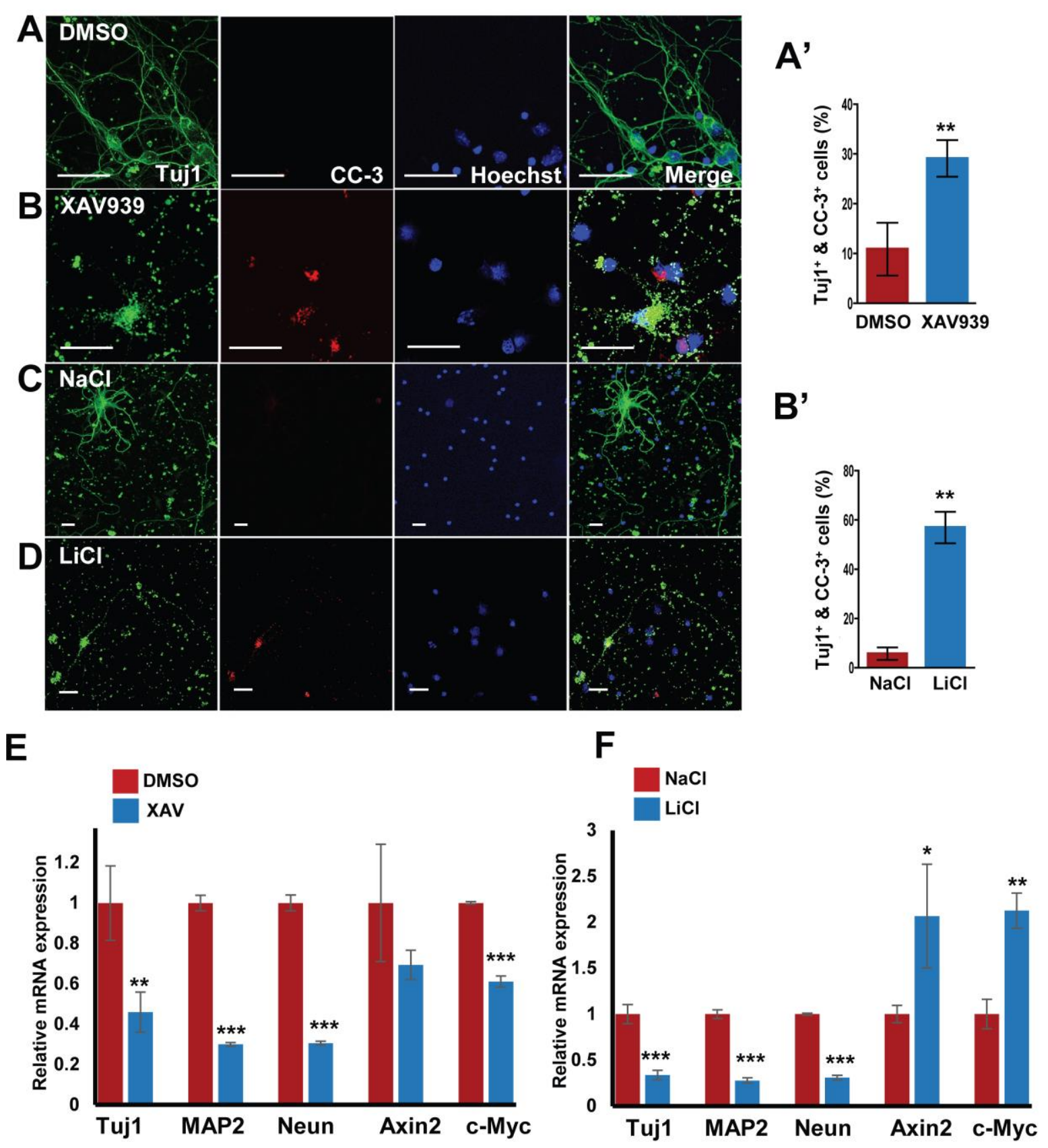




\section{Supplementary Figure 5 (Related to Figure 3)}

A

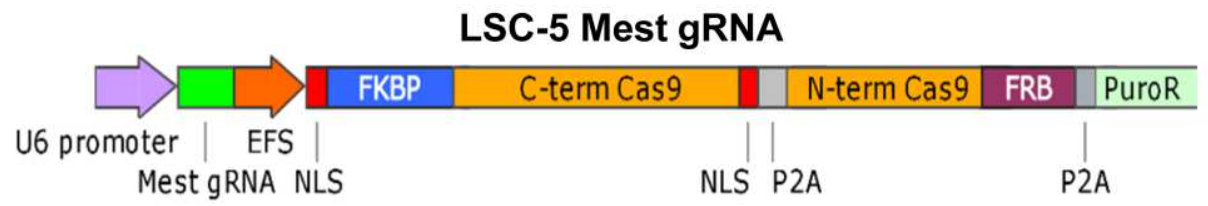

B

P19 LSC-5 Control stable cells

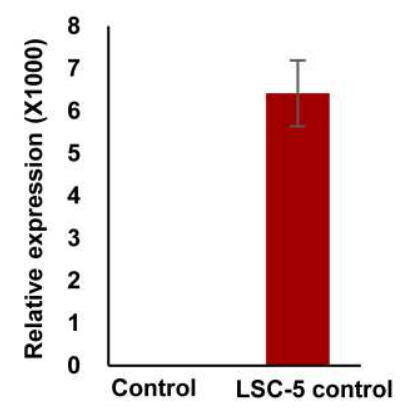

P19 LSC-5 Mest gRNA stable cells

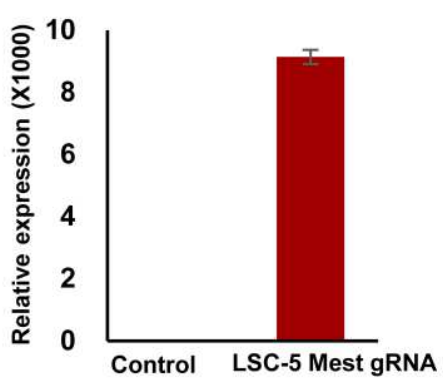


Supplemental Table 1. Clinical characteristics of the non-demented control subjects in the study

\begin{tabular}{ccccccc}
\hline NPID & $\begin{array}{c}\text { Braak } \\
\text { stage }\end{array}$ & Sex & $\begin{array}{c}\text { Cause of } \\
\text { death }\end{array}$ & Age & CDR & $\begin{array}{c}\text { Methylation } \\
\text { Status }\end{array}$ \\
\hline Control 3 & 1 & $\mathrm{~F}$ & N/A & 101 & N/A & Hyper \\
Control 4 & 1 & F & N/A & 87 & N/A & Normal \\
Control 5 & 1 & M & N/A & 88 & 0 & Normal \\
Control 105 & 2 & M & Other & 86 & N/A & Normal \\
Control 114 & 2 & F & Other & 87 & N/A & Normal \\
Control 135 & 3 & M & N/A & 89 & N/A & Normal \\
Control 140 & 1 & M & N/A & 67 & N/A & Normal \\
Control 81 & 1 & M & Other & 82 & N/A & Normal \\
Control 85 & 1 & M & N/A & 67 & N/A & Normal \\
\hline
\end{tabular}

N/A: Not available, CDR: Clinical Dementia Rating

Supplemental Table 2. Clinical characteristics of the Alzheimer's disease subjects in the study

\begin{tabular}{ccccccc}
\hline NPID & $\begin{array}{c}\text { Braak } \\
\text { stage }\end{array}$ & Sex & $\begin{array}{c}\text { Cause of } \\
\text { death }\end{array}$ & Age & CDR & $\begin{array}{c}\text { Methylation } \\
\text { Status }\end{array}$ \\
\hline AD 20 & 5 & M & AD & 82 & N/A & Hyper \\
AD 37 & 6 & F & AD & 79 & N/A & Normal \\
AD 40 & 6 & M & AD & 70 & N/A & Normal \\
AD 41 & 6 & M & AD & 59 & N/A & Normal \\
AD 132 & 5 & F & AD & 80 & N/A & Normal \\
AD 133 & 5 & M & AD & 92 & N/A & Hyper \\
AD 2 & 5 & F & AD & 90 & N/A & Hyper \\
AD 3 & 5 & M & AD & 100 & 3 & Hyper \\
AD 5 & 5 & M & AD & 75 & N/A & Normal \\
\hline
\end{tabular}


Supplemental Table 3. Sequences for gRNA, shRNA and T7E1 assay

\begin{tabular}{|c|c|}
\hline \multicolumn{2}{|l|}{ gRNA sequences } \\
\hline gRNA-Mest-sense & $\begin{array}{l}\text { gtggaaaggacgaaacaccgAAGATTCTGTCGGTGTGGTgtttt } \\
\text { agagctagaaatagc }\end{array}$ \\
\hline $\begin{array}{l}\text { gRNA-Mest- } \\
\text { antisense }\end{array}$ & ccatttgtctcgaggtcgagCAGGAAACAGCTATGACC \\
\hline \multicolumn{2}{|l|}{ T7E1 primers } \\
\hline $\begin{array}{l}\text { PCR product } \\
\text { (1078 base pairs)- F }\end{array}$ & TGACCCCCTCTCATGGGTTA \\
\hline $\begin{array}{l}\text { PCR product } \\
\text { (1078 base pairs)- } R\end{array}$ & GGAGAGCGTAACTCCAGCTT \\
\hline $\begin{array}{l}\text { PCR product } \\
\text { ( } 441 \text { base pairs)- } F\end{array}$ & GTCCTGTCAGCTTGCTTTCTAACA \\
\hline $\begin{array}{l}\text { PCR product } \\
\text { ( } 441 \text { base pairs)- } R\end{array}$ & GGAGAGCGTAACTCCAGCTT \\
\hline \multicolumn{2}{|l|}{ shRNA sequences } \\
\hline shMest1 & $\begin{array}{l}\text { CACCGGCCATTGGATCCTATAAATCGAAATTTATAGGA } \\
\text { TCCAATGGCC }\end{array}$ \\
\hline shMest 2 & $\begin{array}{l}\text { CACCGCCACATCAGTACTCCATATCGAAATATGGAGTA } \\
\text { CTGATGTGG }\end{array}$ \\
\hline
\end{tabular}


Supplemental Table 4. Primers used for qPCR, Mest promoter amplification

\begin{tabular}{|c|c|}
\hline \multicolumn{2}{|c|}{ qPCR primers } \\
\hline Mest-F & CTGGGAAGGGCTGACCCTGAGGTTC- \\
\hline Mest-R & CCATTCGACAGACAGAGACTCTTTATG \\
\hline Tuj1-F & TAGACCCCAGCGGCAACTAT \\
\hline Tuj1-R & GTTCCAGGTTCCAAGTCCACC \\
\hline NeuN-F & CAACATCCCCTTCCGGTTC \\
\hline NeuN-R & TGACCTCAATTTTCCGTCCC \\
\hline Axin2-F & ATTCGGCCACTGTTCAGACG \\
\hline Axin2-R & GACAACCAACTCACTGGCCTG \\
\hline$\beta$-Actin-F & GCGGGAAATCGTGCGTGACATT \\
\hline$\beta$-Actin-R & GATGGAGTTGAAGGTAGTTTCGTG \\
\hline GAPDH-F & CGACTTCAACAGCAACTCCСACTCTTCC \\
\hline GAPDH-R & TGGGTGGTCCAGGGTTTCTTACTCCTT- \\
\hline \multicolumn{2}{|c|}{ Primers for bisulfite sequencing of Mest promoter region } \\
\hline Mest-F & TC/TGTTGTTGGTTAGTTTTGTAC/TGGTT \\
\hline Mest-R & AAAAATAACACССССТССТСАAАТ \\
\hline
\end{tabular}




\section{Figures}

A

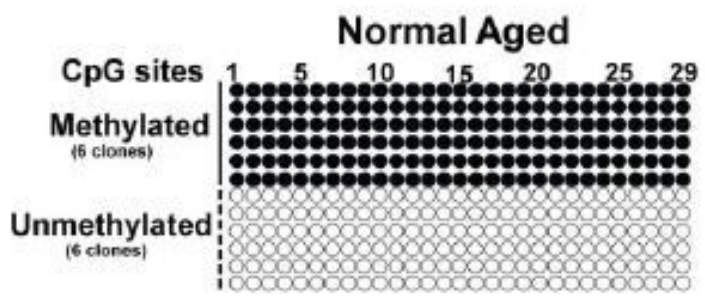

B

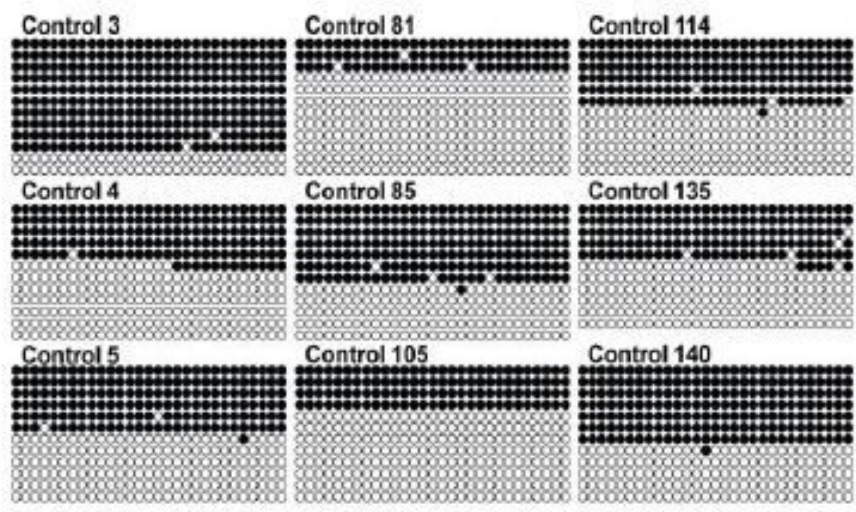

D

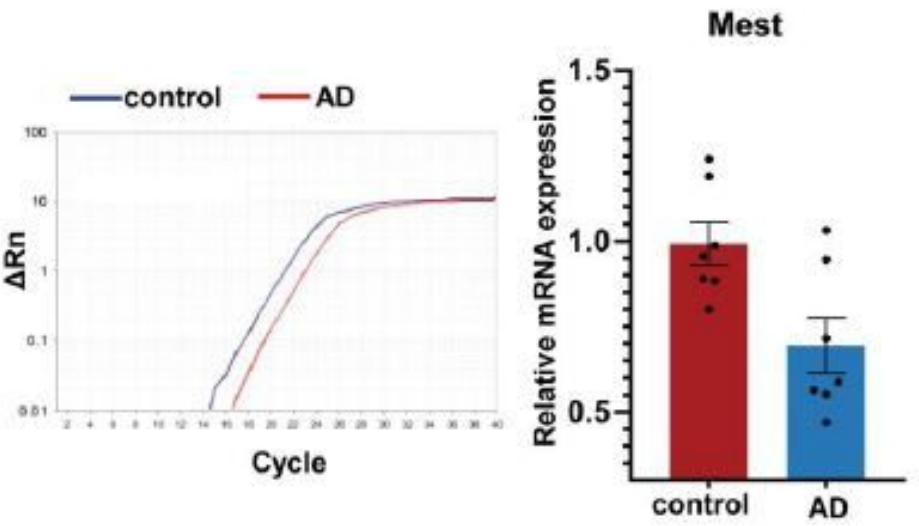

C

\begin{tabular}{cccc}
\hline Gene & Methylation & $\begin{array}{c}\text { AD } \\
(\mathrm{n}=9)\end{array}$ & $\begin{array}{c}\text { NA } \\
(\mathrm{n}=9)\end{array}$ \\
\hline \multirow{2}{*}{ Mest } & Hyper & $44.4 \%$ & $11.1 \%$ \\
& Hypo & $22.2 \%$ & $11.1 \%$ \\
H19 & Hyper & $22.2 \%$ & $0 \%$ \\
& Hypo & $33.3 \%$ & $22.2 \%$ \\
\hline
\end{tabular}

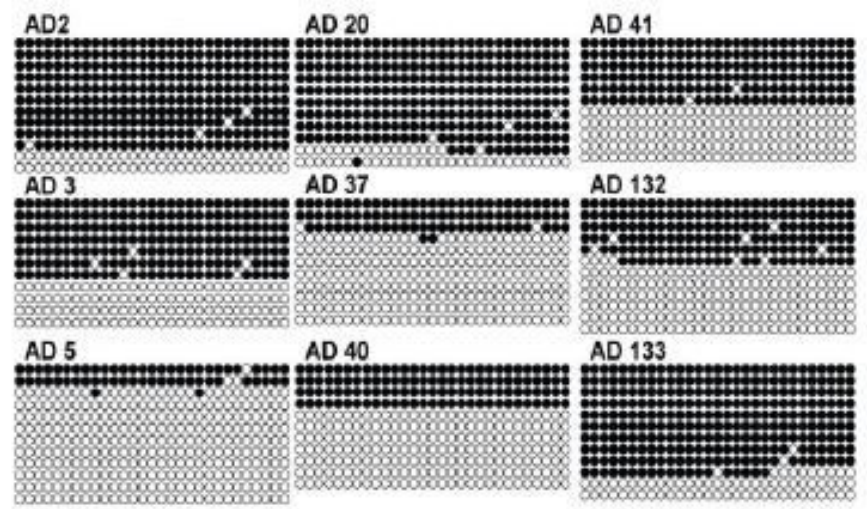

$\mathbf{E}$

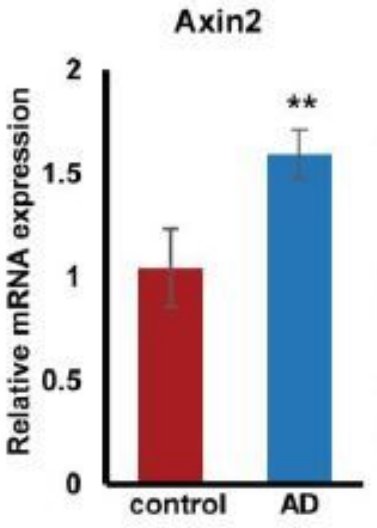

c -Myc

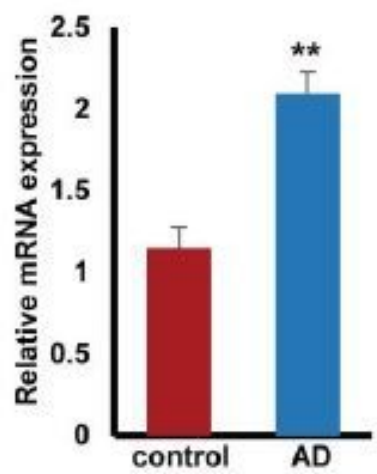

\section{Figure 1}

Hypermethylation of Mest promoter and upregulation of Wnt signaling in brain samples of AD patients. A. Representative example of cytosine methylation pattern of Mest promoter region in DNA extracted from the brain of normal aged subjects. Each row of circles represents a single cloned allele with at least 12 clones sequenced per subject. The white circles represent nonmethylated $\mathrm{CpG}$ site and black circles for methylated cytosines. There are $29 \mathrm{CpG}$ sites in each row. B. Comparison of $\mathrm{CpG}$ methylation patterns within the Mest promoter in DNA isolated from the cortex of normal aged (NA) ( $n=9)$ and AD subjects $(n=9)$ show elevated hypermethylation alleles in AD subjects. C. The summary of Mest and H19 promoter methylation in normal aged (NA) $(n=9)$ and $A D(n=9)$ subjects. $D$. The mRNA levels of Mest is decreased 
in AD patients. Amplification plot (red line) analysis showed a delayed in SYBR Green signal, indicating a decrease of Mest expression in the AD patient as compared to the normal control (blue line). The mRNA of Mest is downregulated in the temporal cortex of sporadic AD postmortem brains $(n=7)$ in comparison to normal subjects $(n=7)$. GAPDH was used for normalizing Mest expression. *, Significantly different from the control at $p<0.01$. E. The mRNA levels of Wnt target genes Axin2 and $c-M y c$ were increased in AD subjects $(n=6)$. mRNA levels were normalized to $\beta$-actin. Data shown as mean $\pm S D ; *, p<.05 ; * \star, p<.01$; $\star \star \star, p<.001$ compared with the corresponding control group. Student's $t$ test was used for statistical analysis.

A

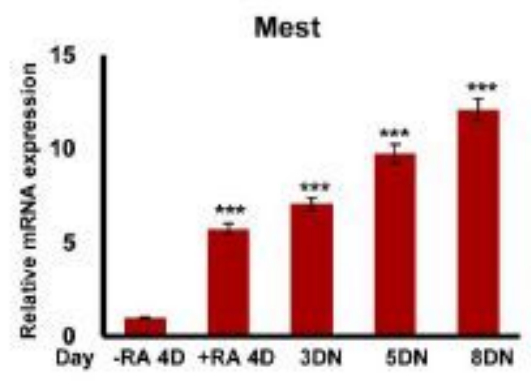

C

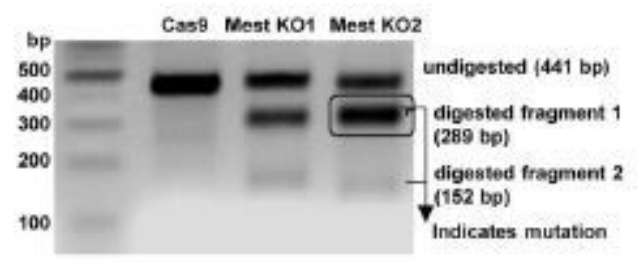

D

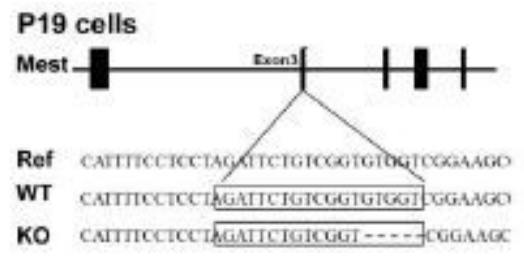

E

\section{$\mathbf{F}$}

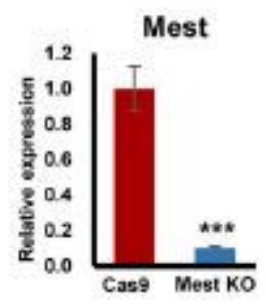

B

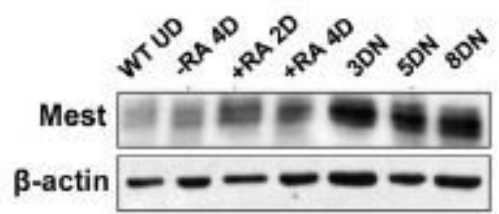

G
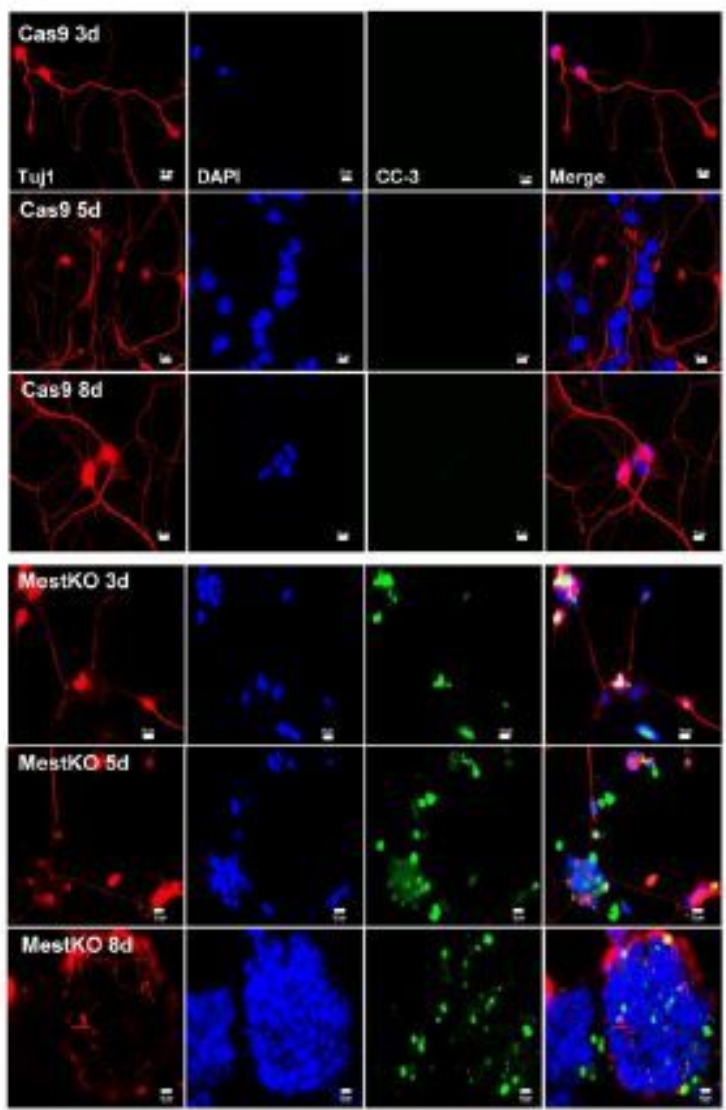

\section{Figure 2}

Mest KO in P19 embryonic carcinoma leads to neuron differentiation blockade. A. qPCR analyses for Mest mRNA expression during neuronal differentiation. Total RNAs were isolated at the indicated times. 
B. Mest protein levels in retinoic acid induced P19 neuronal differentiation. C. T7E1 assay for P19 Mest KO cells. PCR products are generated from the genomic DNA of P19 Mest knockout cells. The PCR products are annealed \& digested with T7 Endonuclease I. Fragments are analyzed to determine the efficiency of genome targeting. D. The P19 Mest KO cells showed 5 base pair deletion near gRNA targeted site upon Sanger sequencing. E. qPCR analyses for Mest mRNA expression in P19 Mest KO cells. F. Mest protein levels in P19 Cas 9 and Mest KO cells. G. Mest KO caused neuron differentiation blockade in P19 cells. P19 differentiated neurons were fixed and immunostained with anti-Tuj1 (red) and cleaved caspase3 ((CC-3), (green)) antibodies at indicated times. Scale bars, $10 \mu \mathrm{m}$. mRNA levels were normalized to $\beta-$ actin. Data shown as mean $\pm S D ; * \star \star, p<.001$; compared with the corresponding control group. Student's $\mathrm{t}$ test was used for statistical analysis. 
A
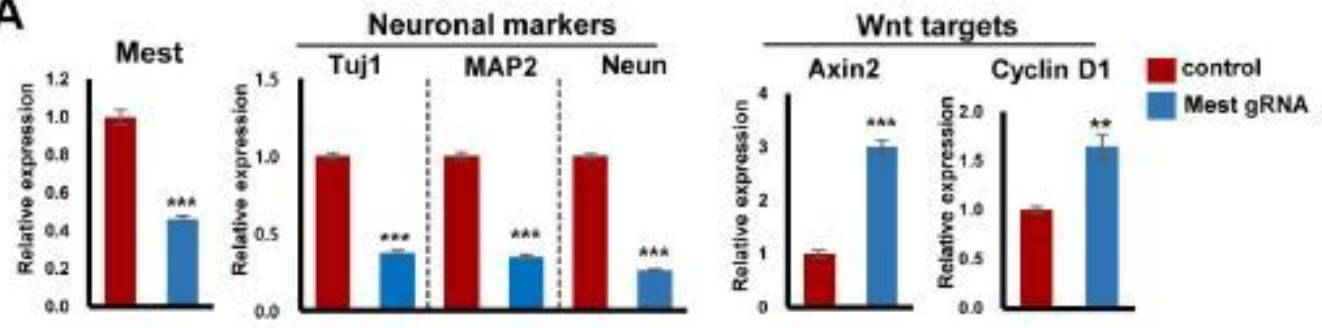

B

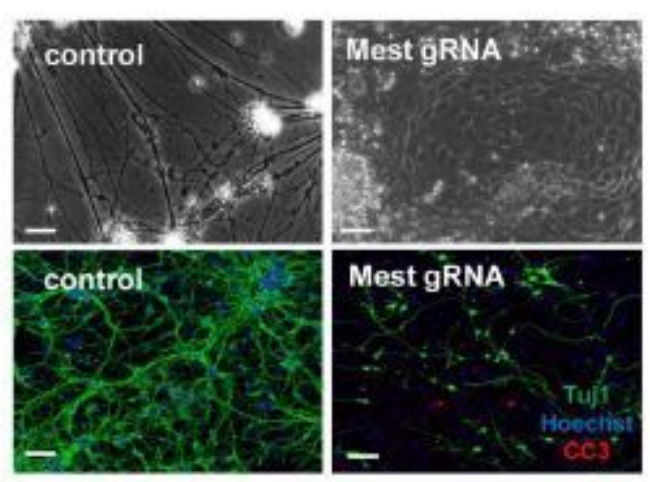

C

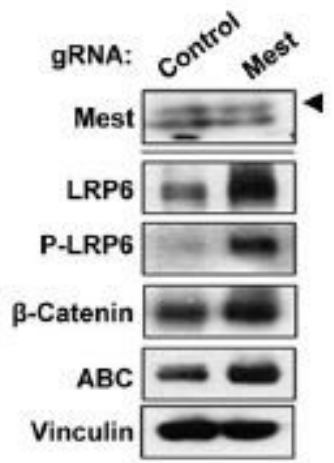

D
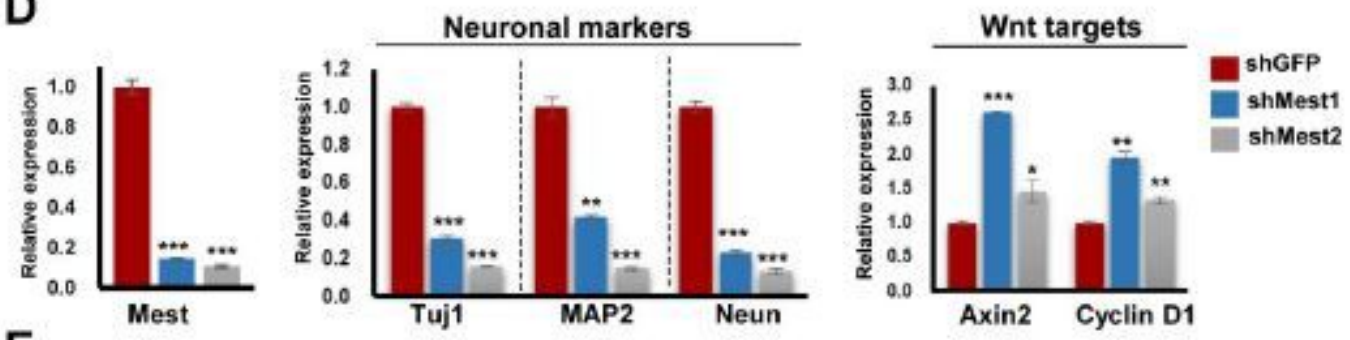

E

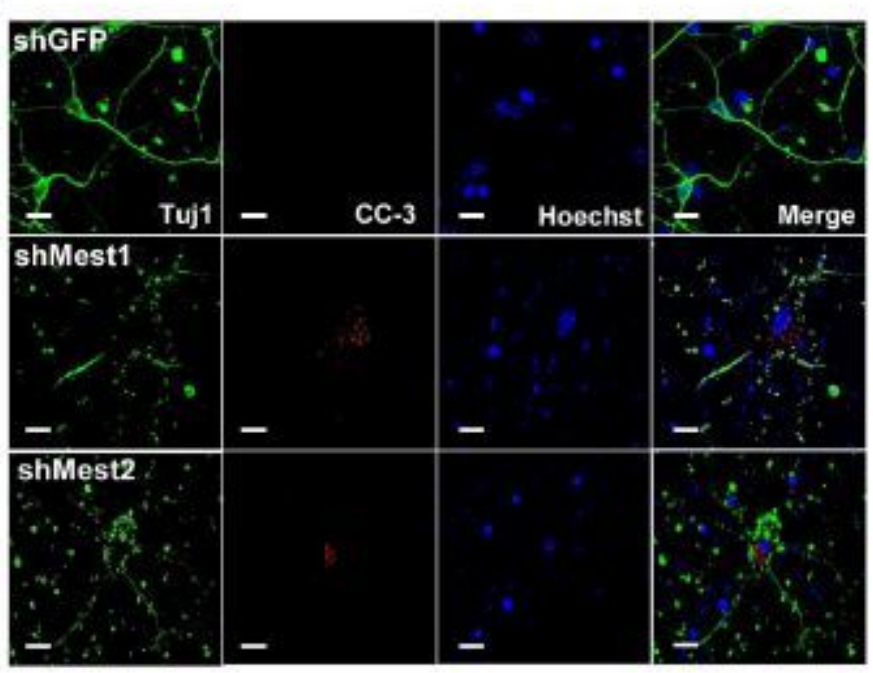

$\mathbf{F}$

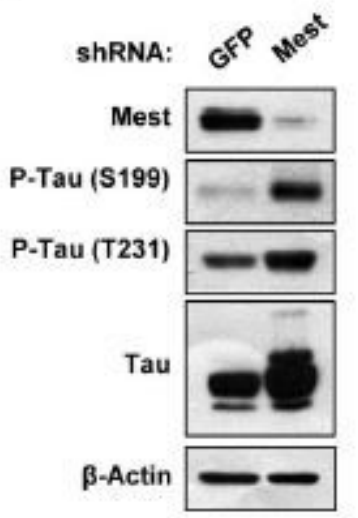

\section{Figure 3}

Mest depletion results in elevation of Wnt signaling and Tau phosphorylation causing neurodegeneration. A. Relative mRNA expression for Mest, neuronal markers and Wnt target genes in 11day neurons of P19 LSC-5 control and Mest gRNA stable cells treated with rapamycin. B. Inducible knockout of Mest caused the neurodegeneration in P19 Mest gRNA stable cells. P19 LSC-5 neurons treated with rapamycin were fixed and immunostained with anti-Tuj1 (green) and cleaved caspase-3 ((CC-3), (red)) antibodies. Phase contrast (top panels, scale bars, $100 \mu \mathrm{m}$ ) and fluorescent images (bottom panels) of 11 day neurons of 
P19 LSC-5 control and Mest gRNA stable cells induced with rapamycin. Scale bars, $88 \mu \mathrm{m}$. C. Deficiency of Mest leads to increased Wnt signaling. Western blotting for Mest, and Wnt signaling components LRP6, p-LRP6, $\beta$-catenin, Active $\beta$ catenin (ABC) in P19 Mest inducible KO cells isolated from (B) was performed. Vinculin was used as a loading control. Filled arrow indicates specific band. D. qPCR analysis for Mest, neuronal markers and Wnt target genes in DIV7 hippocampal neurons infected with lentiviral shMest. E. Mest knockdown caused the neurodegeneration in hippocampal neurons. DIV7 hippocampal neurons treated with lenti-shMest were immunostained with anti-Tuj 1 (green) and cleaved caspase-3 ((CC-3), (red)) antibodies. Scale bars, 18 $\mu \mathrm{m}$. F. DIV7 rat hippocampal neurons treated with shMest lentivirus showed increase of tau phosphorylation at S199, and Thr231 sites. All mRNA levels were normalized to $\beta$-actin. Data shown as mean $\pm S D ; *, p<.05 ; * \star, p<.01 ; * \star \star, p<.001 ; * \star \star \star, p<.0001$ compared with the corresponding control group. Student's t test was used for statistical analysis.

\section{Supplementary Files}

This is a list of supplementary files associated with this preprint. Click to download.

- figS1.jpg

- figS2.jpg

- figS3.jpg

- figS4.jpg

- figS5.jpg

- Tables1.jpg

- Tables2.jpg

- TableS3.jpg

- Tables4.jpg 